\title{
ANOMALIES IN ESTIMATES OF CROSS-PRICE ELASTICITIES FOR MARKETING MIX MODELS: THEORY AND EMPIRICAL TEST
}

\author{
Andre Bonfrer \\ Ernst R. Berndt \\ Alvin Silk \\ Working Paper 12756 \\ http://www.nber.org/papers/w12756 \\ NATIONAL BUREAU OF ECONOMIC RESEARCH \\ 1050 Massachusetts Avenue \\ Cambridge, MA 02138 \\ December 2006
}

The views expressed herein are those of the author(s) and do not necessarily reflect the views of the National Bureau of Economic Research.

(C) 2006 by Andre Bonfrer, Ernst R. Berndt, and Alvin Silk. All rights reserved. Short sections of text, not to exceed two paragraphs, may be quoted without explicit permission provided that full credit, including $\odot$ notice, is given to the source. 
Anomalies in Estimates of Cross-Price Elasticities for Marketing Mix Models: Theory and Empirical Test

Andre Bonfrer, Ernst R. Berndt, and Alvin Silk

NBER Working Paper No. 12756

December 2006

JEL No. D12,M30

\begin{abstract}
We investigate the theoretical possibility and empirical regularity of two troublesome anomalies that frequently arise when cross-price elasticities are estimated for a set of brands expected to be substitutes. These anomalies are the occurrence of: (a) negatively signed cross-elasticities; and (b) sign asymmetries in pairs of cross price elasticities. Drawing upon the Slutsky equation from neoclassical demand theory, we show how and why these anomalies may occur when cross elasticities are estimated for pairs of brands that are substitutes. We empirically examine these issues in the context of the widely used Multiplicative Competitive Interaction (MCI) and Multinomial Logit (MNL) specifications of the fully extended attraction models (Cooper and Nakanishi 1988). Utilizing a database of store-level scanner data for 25 categories and 127 brands of frequently purchased branded consumer goods, we find that about $18 \%$ of a total of 732 cross elasticity estimates are negative and approximately $40 \%$ of the 366 pairs of cross elasticities are sign asymmetric. Finally, we find that the occurrence of negatively signed cross elasticities can be partially explained by a set of hypothesized relationships between cross-price elasticities and brand share and elasticities of income and category demand.

Andre Bonfrer

Singapore Management University

50 Stamford Road \#05-01

Singapore 178899

andrebonfrer@smu.edu.sg

Ernst R. Berndt

Sloan School of Management

MIT, E52-452

50 Memorial Drive

Cambridge, MA 02142

and NBER

eberndt@mit.edu

Alvin Silk

Graduate School of Business Administration

Harvard University

Soldiers Field

Boston, MA 02163

asilk@hbs.edu
\end{abstract}




\section{INTRODUCTION}

One of the most perplexing puzzles empirical researchers confront when analyzing category-level data in order to estimate substitution matrices are results that appear to contradict both economic theory and managerial insight. For example, many studies of cross elasticities show that the sales of competing products are negatively related to the prices of those products. Such estimates not only seem to violate economic theory regarding product substitutes but also pose a managerial dilemma: why would the sales of my product increase when my competitor lowers his price? The objective of this paper is to shed light on this puzzle and to provide insights into what patterns of results can be expected from estimates of price-based substitution matrices.

More specifically, we address two related problems encountered in many empirical studies when one seeks to employ flexible demand specifications for market share models (such as the "fully extended" versions of either the Multiplicative Competitive Interaction (hereafter MCI) or the Multinomial Logit (MNL) models, also referred to as the Exponential Competitive Interaction (ECI) model). ${ }^{1}$ Flexible demand specifications directly incorporate the concept of differential cross-competitive effects and have other desirable properties (Cooper and Nakanishi 1988, Cooper 1993, Fok, Frances, and Paap 2002).

The first problem with flexible specifications of market share response models is that they occasionally yield cross-price elasticities that are negative and statistically significant, even when there are good reasons for expecting that the brands are substitutes. Second, because flexible models allow differential cross effects to be asymmetric with respect to not only magnitude, but also sign, the situation arises where, for example, the estimate of the

\footnotetext{
${ }^{1}$ Hanssens, Parsons, and Schultz (2001, p. 124) advocate use of the ECI label rather than MNL to avoid confusing the MNL/ECI share model with the logit model of individual-level demand or brand choice.
} 
cross elasticity reflecting the influence of $i$ 's price on $j$ 's market share has the opposite sign to the estimate pertaining to the effect of $j$ 's price on $i$ 's market share. This leads to an interpretive quandary: such a result seemingly indicates that a pair of brands are simultaneously substitutes and complements.

It is interesting to note that the phenomenon of negative cross-elasticities has been documented across a number of studies reported in the marketing science literature. For example, in their meta-analysis, Sethuraman, Srinivasan and Kim's (1999) found that negative cross-elasticities accounted for about $10 \%$ of the 1,060 cross-price elasticities they assembled from 15 published studies. These authors included the negative cross-elasticity estimates in their meta-analysis but posited that they are likely due to measurement errors.

The doubtful presence of negative cross-elasticities in market response models has led researchers to develop techniques to reduce or even eliminate their occurrence. For example, Bucklin, Russell and Srinivasan (1998, herein BRS) show positive substitution patterns can be assured by relating the cross elasticities to the row-conditional brand switching probabilities based on individual level data and aggregated to the corresponding market level. Since brand switching probabilities are always positive, the resulting market share elasticities are also positive. In an empirical application for nine brands of liquid laundry detergents, BRS also present an unrestricted fully-extended MCI attraction model for which $38 \%$ of the elasticities that are negative. Similarly, many multinomial logit and probit specifications use a single parameter for the price coefficient. An appealing feature of such models is that the cross elasticities ${ }^{2}$ are based on the own-price coefficient and as long as this coefficient is negative in value, the cross elasticity will always be positive.

\footnotetext{
${ }^{2}$ See Ben-Akiva and Lerman (1985) for derivation of the logit market share elasticities. The own-price
} 
This paper adopts a different perspective and raises the issue of whether these negative substitution rates are indeed incorrect, or whether they represent a real phenomenon in substitution patterns that can be analyzed and interpreted. In this spirit, we address the issues of both negative and asymmetric-signed cross elasticities in the general context of quantity-based market share models. We begin by providing a theoretical rationale for these phenomena and then conduct an empirical assessment of predictions stemming from this theory. The following research questions are directly addressed in this paper:

1) Is it theoretically possible for signs of cross-elasticities to be negative for a set of brands that are substitutes? As a corollary of negative signs, is it possible for a pair of cross elasticities to be asymmetric in sign?

2) Does empirical evidence support hypotheses stemming from the theoretical underlying patterns of signs in cross-elasticities?

The theoretical findings are based on an application of the well-known Slutsky equation from demand theory (Deaton and Muellbauer 1980) to the context of quantity based market share models. As an illustration of this effect, consider the theoretical substitution pattern between two competing brands of liquid laundry detergents: Tide (P\&G) and Wisk (Unilever). Figure 1 presents the classic indifference curve analysis often used in utility theory to explain the difference between compensated and uncompensated tradeoffs. The indifference curves are given by the parallel curved lines, $U_{1}$ and $U_{2}$. The horizontal axis represents the demand for Tide $\left(X_{\text {Tide }}\right)$ and the vertical axis is demand for Wisk $\left(X_{\text {Wisk }}\right)$.

elasticity is $e_{i i}=\beta_{p}\left(1-m s_{i}\right)$ where $m s_{i}$ is the market share for brand $i, \beta_{p}$ is the estimated price coefficient from the logit model and $e_{i i}$ is the uncompensated own price elasticity. The corresponding cross-elasticity is $e_{i j}=-\beta_{p} m s_{j}$ for $i \neq j$. Since $\beta_{p}$ is typically negative in estimation the cross elasticity is usually positive. 
The straight lines $\left(I_{0}, I_{1}\right.$ and $\left.I^{*}{ }_{1}\right)$ represent budget constraints. Since the optimal consumption bundle is at the point where the highest indifference curve is attained, the best point for this set of prices is $A$.

\section{INSERT FIGURE 1 HERE}

The first consequence of a change in the price for Solo (here a price decrease) is a shift and rotation of the budget constraint out to $I_{l}$. The new optimal point is at $B$. The uncompensated cross price elasticity for Tide given Wisk's price change is given by the relative change in the demand for Tide given the relative change in the price for Wisk, or $\left(\Delta X_{\text {Tide }} / X_{\text {Tide }}^{0}\right) /\left(\Delta p_{\text {Solo }} / p_{\text {Solo }}^{0}\right)$. Under consumer demand theory, there is no property that restricts this value to be positive. Indeed, from Figure 1, the quantity demanded of Tide actually increases in response to the Wisk price decrease. The general possibility of negative cross-effects has been acknowledged (see Deaton and Muellbauer, 1980) and arises because the income effect of the price change overwhelms the substitution effect.

The substitution effect in Figure 1 is the movement from point $A$ to point $C$. This substitution effect is often called the "compensated" elasticity (e.g. see Allenby and Rossi 1991, Montgomery and Rossi 1999b) since it involves the bundle of consumption chosen if customers were given enough money (i.e. compensated) to attain the utility available from the original choice $(A)$ which means moving the budget constraint to $I_{1}^{*}$. A well known property of the compensated price elasticity is that it must always be positive, although, as we will discuss, it is not required to be symmetric - also see Montgomery and Rossi 1999 on this point.

What is not well understood is how often and under what circumstances that negative cross elasticities arise. It is also not well known how this relation translates into 
market share elasticities. The theoretical analysis presented in this paper is concerned with the properties of the decomposed cross-elasticities in the context of market share response models. This analysis reveals that asymmetries are a natural property of market share response models. Moreover, standard consumer demand theory does not rule out the possibility of asymmetric and negative signs in market share models. We extend our theoretical analysis to derive the conditions under which one may expect these properties to surface in estimation of market share response models.

In the marketing science literature there are few market response models which consider the difference between compensated and un-compensated elasticities. Notable exceptions include Allenby and Rossi (1991b) and Montgomery and Rossi (1999). Montgomery and Rossi (1999) develop a method to measure compensated price (brand quantity) elasticities directly. An important feature of compensated elasticities is that they must (in theory) be positive since they measure movements along a fixed indifference curve. Allenby and Rossi (1991b) develop an individual level discrete choice model for which magnitude asymmetries in cross-elasticities are explained by opposing effects of inferior versus superior brands’ income elasticities. Our work closely complements this stream of literature by studying market share elasticities with a similar decomposition of elasticities into income and substitution effects.

As the above discussion indicates, conventional wisdom is that negative estimates of cross-price elasticities are incorrect (“wrong-signed”). As a corollary, asymmetric signs for cross elasticities must also be implausible. Our analysis suggests that negative signs can occur in cross-elasticities (or absolute cross-effects) whenever a combination of the following conditions holds: 
1) There is a high income elasticity for the competing brand, especially when the focal brand's budget share is large,

2) There is a high category demand price elasticity for the competing brand,

3) The Hicksian (or compensated) substitution rate between the two brands is small relative to 1) or 2).

These results are very general - they apply for any quantity- based market share equation, regardless of the specification studied.

We conduct an empirical study to document the extent to which such apparently anomalous results occur. The empirical application is based on data for 25 FMCG categories in the context of the fully-extended attraction based models - in particular, the MCI and the MNL/ECI specifications for market share. The choice of categories studied is such that, a priori, all alternatives are expected to be substitutes - i.e. to yield positive crossprice elasticities.

A summary of the empirical estimates consisting of 732 cross-elasticities reveals that negative signs occurred in about $18 \%$ of possible instances (depending on the model specification used) and asymmetric signs occurred in about $40 \%$ of cases. Out of 25 categories studied, for only seven categories were all the cross-elasticity estimates positive. Finally, we find that our hypothesized relationships between the cross elasticities and income effects, brand share, and category demand elasticity can partially explain these patterns in the cross effects.

The paper is structured as follows. Section 2 reviews the theoretical background for quantity-based market share models from the perspective of the neoclassical theory of consumer demand. Section 3 considers the decomposition of the market share elasticity 
based on the Slutsky relation and a set of testable hypotheses is derived from this decomposition. Section 4 describes the database for which MCI and MNL/ECI market share models are applied to estimate a large cross-section of price elasticities used in testing hypotheses. In Section 5 we present our results and in Section 6 we discuss the implications of our theoretical and empirical findings. Section 7 presents the conclusion from this analysis and discusses potential further research.

\section{CONSISTENCY REQUIREMENTS FOR QUANTITY-BASED MARKET SHARE MODELS}

The starting point for the theoretical analysis is a discussion of the properties governing attraction-based models drawn from marketing and economic theory. These are logical consistency, homogeneity, and symmetry. In this paper we focus primarily on symmetry requirements and develop the symmetry properties of market share models. These properties are then analyzed to formulate a set of hypotheses that are subsequently subjected to empirical tests.

\section{$\underline{\text { 2.1 Logical Consistency }}$}

By definition, the share of any brand must fall within the zero-one interval (the “range” restriction), and shares summed over all brands within a product category must always equal one (the "sum” constraint). The range restriction further requires that the maximum of any of the alternatives be greater than zero and less than one. The scope of this paper is focused on cross elasticities estimated within the class of models that satisfy the logical consistency requirements (cf., Naert and Bultez 1973, McGuire and Weiss 1976, Weverbergh, Naert, and Bultez 1981). 
Formally, define the market (quantity) share of the $i^{\text {th }}$ brand as $s_{i}=q_{i} / \sum_{v=1}^{m} q_{v}$ where $q_{i}$ is quantity sold of brand $i$. By definition, the share of any brand must fall within the zero-one interval and shares summed over all brands in a category must always equal one, i.e.,

$$
\sum_{i=1}^{m} s_{i}=1,0<s_{i}<1, \text { for all } i=1, \ldots, m
$$

Logical consistency requires a bit more, however. Let there be a set of factors affecting the $s_{i}$, denoted by $X_{h}, h=1, \ldots, H$ where $h$ denotes a particular marketing mix variable (e.g. price, advertising) affecting the $i^{\text {th }}$ brand:

$$
s_{i}=g\left(X_{1}, X_{2}, \ldots, X_{H}\right), i=1, \ldots, m
$$

where $g()$ is a continuous and at least once differentiable function. Since shares must always sum to unity, it follows that:

$$
\sum_{i=1}^{m} \frac{\partial s_{i}}{\partial X} \equiv 0 \quad \forall h \in 1, \ldots, H
$$

Hereafter we refer to (3) as the "zero sum” constraint, and note that it is required for logical consistency.

To avoid unnecessary complexity, we focus our attention on price and represent price using the $X$ variable. In the analysis that follows, it will be useful to construct an $m \times H$ matrix whose elements correspond to the effects of variable $X_{h}$ on the market share of brand $i$. Let the rows of this matrix represent $m$ brands, and let the columns represent $H$ explanatory variables affecting the $m$ brand market shares. Let a typical element of this $\mathrm{F}$ matrix be, $f_{\text {ih }}$ where: 


$$
f_{i h}=\frac{\partial s_{i}}{\partial X_{h}}
$$

Thus, this F matrix of derivatives is of the form:

$$
\text { Brands } \quad F=\left[\begin{array}{rrrrr}
f_{11} & f_{12} & f_{13} & \ldots & f_{1 \mathrm{H}} \\
f_{21} & f_{22} & f_{23} & \ldots & f_{2 \mathrm{H}} \\
f_{31} & f_{32} & f_{33} & \ldots & \\
\ldots & \ldots & \ldots & \ldots & \ldots \\
f_{\mathrm{m} 1} & f_{\mathrm{m} 2} & f_{\mathrm{m} 3} & \ldots & f_{\mathrm{m} \mathrm{H}}
\end{array}\right]
$$

Note that the zero sum constraints (3) imply that the column sums of $F$ in (5) must all equal zero, i.e.

$$
\sum_{i=1}^{m} f_{\text {ih }}=0, \text { for all } h=1, \ldots, H
$$

For the remainder of this paper we focus on the role of price in the market share response function and (for notational convenience) represent price using the non-subscripted $X$ variable. The focus on price means that $H=1$ and that the matrix in Eq. (5) is of dimension $m \times 1$.

\subsection{Market Share Models and Economic Theory}

Additional restrictions on the $f_{i}$ responses can be derived from the economic theory of demand, as was originally noted by McGuire, Weiss and Houston (1977) who proposed that "economic consistency" be added to the list of desiderata for market share models along with logical consistency. Except for studies by Houston, Kenetkar, Stacey and Weiss (1991), Montgomery and Rossi (1999), and Montgomery (2002), the literature on market share response models appears to have paid limited attention to the matter of economic consistency. Here we consider two basic properties of demand functions specified by the 
economic theory of consumer behavior (Deaton and Muellbauer 1980 pp. 43-46): requirements for homogeneity, and for symmetry.

2.2.1 Homogeneity Requirements. Let $X_{1}$ through $X_{m}$ be the prices of brands 1 through $m$, and let $X_{m+1}$ be money income. According to basic economic theory (Deaton and Muellbauer 1980, Chapter 1), demand functions should not be subject to money illusion, but instead should be homogenous of degree zero in prices and income. More specifically, suppose that the prices of all $m$ products and money income are increased by the same percentage amount, $\Delta X_{i} / X_{i} \cong \Delta \ln X_{i} \forall i=1, \ldots m+1$. In this case, although nominal prices and nominal income all change by the same proportion, relative (or "real”) prices and (“real”) income are unaffected. According to demand theory, when relative prices and real income are unaffected, quantities demanded and therefore quantity shares also remain unchanged. Moreover, this result does not require that one make the restrictive assumption that all consumers share identical preferences. As has been shown by Sonnenschein (1973), even if preferences of individual economic units differ, the aggregate demand functions must still be homogenous of degree zero in prices and income, i.e.,

$$
\sum_{i=1}^{m+1} \frac{\partial s_{i}}{\partial \ln X_{i}}=\sum_{i=1}^{m+1} f_{i} X_{i}=0
$$

Note that the homogeneity requirements (7) imply a different type of sum constraint from the column sum restriction (6) required for logical consistency. In particular (7) is a row constraint involving a different matrix having one more column and $f_{i h} X_{h}$ elements rather than $f_{\text {ih }}$ in (5). Thus we call the row sum restrictions in (7) homogeneity restrictions, and note that they are required to ensure consistency with economic theory. 
2.2.2 Symmetry Requirements. Is it theoretically possible for a pair of cross elasticities for two brands to be asymmetric with respect to their signs? The well-known Slutsky equation from neoclassical demand theory provides the framework needed to analyze this question (Deaton and Muellbauer 1980, pp. 45-6). The Slutsky equation decomposes the observable cross-effects of a change in the price of good $j\left(X_{j}\right)$ on the quantity demanded of good $i$ $\left(q_{i}\right)$ into two components: (a) the "compensated price effect" representing the substitution effect along an indifference curve rate where a consumer's utility $(u)$ remains unaffected; and (b) the "income" effect indicating how $q_{i}$ increases or decreases with changes in income $\left(X_{m+1}\right)$, shifting the indifference curve but holding prices constant.

In Appendix A, the Slutsky equation is derived in terms of quantity market shares rather than quantity levels. For an individual consumer, this leads to the following decomposition of market share $\left(s_{i}\right)$ cross elasticities $\left(E_{i j}\right)$ with respect to price $\left(X_{j}\right)$.

$$
\begin{gathered}
E_{i j} \equiv \frac{\partial \ln s_{i}}{\partial \ln X_{j}}=\left.\frac{\partial \ln q_{i}}{\partial \ln X_{j}}\right|_{\mathrm{u}=\text { constant }}-\left.B_{j} \frac{\partial \ln q_{i}}{\partial \ln X_{m+1}}\right|_{\text {Prices=constant }} \\
-\frac{\partial \ln \left(\sum_{v=1}^{m} q_{v}\right)}{\partial \ln X_{j}}
\end{gathered}
$$

for any $i \neq j$, where $B_{j}$ is the share of the consumer's total category expenditures or budget allocated to good $j$ :

$$
\mathrm{B}_{\mathrm{j}}=\frac{X_{j} q_{j}}{\sum_{v=1}^{m} X_{v} q_{v}}
$$

The first two terms on the right hand side of Eq. (8) are market share analogs to the components of the (Marshallian) quantity demand-based Slutsky decomposition: the “compensated" cross price elasticity ( $\partial \ln q_{i} / \partial \ln X_{j}, \mathrm{u}=$ constant) and the competing 
brand's budget share (not quantity share) weighted by the focal brand's income elasticity $\left(B_{j} \times\left(\partial \ln q_{i} / \partial \ln X_{m+1}\right)\right.$, prices $=$ constant $)$. The third term is the elasticity of primary or category demand with respect to the price of a particular good, say, $j$ $\left(\partial \ln \left(\sum_{v=v}^{m} q_{v}\right) / \partial \ln X_{j}\right)$

The sign of the first component of Equation (8) defines whether the relationship between the two goods is one of substitutability (positive) or complementarity (negative). Moreover, a key result from demand theory is that the compensated price effects must be pairwise symmetric with respect to both sign and magnitude (Deaton and Muellbauer 1980, pp. 43-46), i.e.

$$
\frac{\partial q_{i}}{\partial X_{j}}=\frac{\partial q_{j}}{\partial X_{i}}=R(i \& j)
$$

Note however, that Eq. (8) does not imply magnitude symmetry with respect to compensated cross-price elasticities. That is, it is not the case that $\partial \ln q_{i} / \partial \ln X_{j}$ $=\partial \ln q_{j} / \partial \ln X_{i}$ unless, coincidentally, $X_{j} / q_{i}=X_{i} / q_{j}$.

For notational convenience, let us define the income elasticity of brand $i$ as

$$
I_{i}=\frac{\partial \ln q_{i}}{\partial \ln X_{m+1}},
$$

the elasticity of primary or category demand with respect to the price of brand $j$ as

$$
C_{j}=\frac{\partial \ln \left(\sum_{v=1}^{m} q_{v}\right)}{\partial \ln p_{j}}
$$

the compensated cross-price elasticity ( $\partial \ln q_{j} / \partial \ln p_{i}, \mathrm{u}=$ constant $)$ by

$$
E_{i j}^{*}=\frac{X_{j}}{q_{i}} R(i \& j)
$$


We can therefore rewrite Eq. (8), the uncompensated cross-price elasticity $\left(E_{i j}\right)$ as:

$$
E_{i j}=E_{i j}^{*}-\left(B_{j} I_{i}+C_{j}\right)
$$

Given this symmetry of compensated price effects, it becomes apparent that a sufficient condition for the observable share cross-price elasticities to be asymmetric with respect to magnitude is that the sums of the budget share-weighted income elasticity and the category demand elasticity for the two goods be unequal, i.e. $E_{j i} \neq E_{i j}$ when:

$$
E_{i j}^{*}-\left(B_{j} I_{i}+C_{j}\right) \neq E_{j i}^{*}-\left(B_{i} I_{j}+C_{i}\right)
$$

Furthermore, it may be seen from Eqs. (8) and (14) that sign asymmetry may obtain between a pair of cross-elasticities if the following conditions hold:

$$
\begin{array}{ll}
E_{i j}<0, \text { iff }: & \left(B_{j} I_{i}+C_{j}\right)>E_{i j}^{*} \\
E_{j i}>0, \text { iff }: & \left(B_{i} I_{j}+C_{i}\right)<E_{j i}^{*}
\end{array}
$$

where the $E_{i j}^{*}$ 's are compensated price elasticities, as defined by Eq. (13). A parallel set of conditions for sign asymmetry may be defined by reversing the inequalities in Eq. (16).

Thus, if: (a) the income elasticity of one brand, say $i$, multiplied by its budget share, plus the elasticity of total demand with respect to the price of that brand exceeds its compensated cross-price elasticity with another brand, $j$, and, (b) the latter quantity exceeds the sum of the comparable income and category demand elasticities for the other brand, $j$, $\underline{\text { then }}$ the cross elasticities for those two goods will be pairwise asymmetric, both with respect to sign and magnitude.

Having established that such asymmetry is theoretically possible, we naturally ask: What can be said about when one might encounter the conditions identified above for 
magnitude asymmetry (Eq. 15) or sign asymmetry (Eq. 16)? This issue is addressed in Section 3.

It is worth noting that Allenby and Rossi (1991b) have developed a model of brand choice which generates asymmetric responses to price promotions for packaged goods brands differing in quality. The key mechanism which gives rise to the asymmetry in their context is the sign difference in income effects $\left(I_{i}\right.$ and $\left.I_{j}\right)$ between a high versus a low quality brand. In an empirical study of margarine brands, these authors report support for their model.

2.2.3 Measurement Considerations. It also bears noting that Deaton and Muellbauer (1980, p. 45) remark that the law of demand does not preclude the possibility that the (Marshallian) quantity demand elasticity be positive. Their observation is based on the Slutsky decomposition of the Marshallian demand function, and suggests that even though the own-price compensated response must always be negative, it is possible (though not likely) that this be outweighed by a positive income effect for “superior” goods. Goods that follow this behavior are known as Giffen goods, a special sub-class of inferior goods, where the good is highly inferior and purchased in sufficiently large quantities to make the overall demand effect positive. Although they do not comment on cross-elasticities, their argument/logic applies there in an analogous manner.

A further problem which frustrates attempts to diagnose conditions underlying sign asymmetries in empirical work is that the theory underlying the Slutsky decomposition relates to the behavior of a single, utility maximizing consumer. Hence, issues of underlying heterogeneity must be considered in interpreting cross-elasticities estimated from aggregate market share data. In the economics literature, it has been shown that, in general, if 
consumers differ in their preferences, then one would not expect aggregate demand functions to satisfy Slutsky symmetry conditions which apply at the individual level (Sonnenschein 1973; and Diewert 1974, 1977, and 1980).

In a similar vein, Blattberg and Wisniewski (1989) analyze how asymmetries in response to price promotions are affected by the distribution of consumers' preference for packaged goods brands differing in quality. Studies of individual household purchasing of such goods reveal substantial levels of heterogeneity in preferences (Chintaguna, Jain and Vilcassim 1991, Ainslie and Rossi 1998) and in promotional responsiveness (Allenby and Rossi 1991a). The latter authors investigate the bias in cross-price elasticities obtained from an attraction-type model estimated with aggregate data when the population of underlying consumers is heterogeneous. A combination of simulation and analytical techniques is used to assess the performance of an aggregate “nested” logit model which groups packaged goods brands into sub-markets reflecting quality-price differences. They conclude that the use of the aggregate level model is justified when three conditions are met: (i) all consumers are exposed to the same marketing mix variables; (ii) all brands are close substitutes; and (iii) price distributions are not concentrated at extreme values.

Virtually all of this work in marketing on asymmetric competition implicitly or explicitly assumes that the goods under investigation are related to one another only as substitutes - complementarities are specifically excluded. As a result, the focus is on asymmetries in the magnitude of substitution cross effects. Since only positively-signed estimates are expected, negative cross-effects are often dismissed as “wrong-signed” anomalies, irrespective of whether they are pairwise symmetric or asymmetric with respect to sign. Here we take a different position and argue that such anomalies merit deeper 
investigation. Even if there were a bias against presenting and publishing such anomalous results in cross-elasticities, they continue to be reported in empirical studies - possibly suggesting this phenomenon is more widespread than is currently recognized. ${ }^{3}$

Sign asymmetries have been subjected to little in the way of close scrutiny and our understanding of the robustness of cross-elasticities estimated from the extended versions of the aggregate attraction models is very limited. More evidence relating to the properties of estimates obtained from aggregate attraction models similar in spirit to Allenby and Rossi's (1991a) and Christen, Gupta, Porter, Staelin, and Wittink’s (1997) studies of aggregation bias would constitute useful contributions to the existing literature.

Overall then, whereas theoretical explanations such as differential income effects between pairs of goods differing in quality may be invoked to account for asymmetries in the magnitudes of cross-price elasticities, it is difficult to offer a plausible substantive interpretation for asymmetries in the signs of cross-price effects, other than the operation of various threats to the statistical conclusion validity of the estimates, such as aggregation bias, over-parameterization, collinearity and the like.

\section{PREDICTIONS FROMTHEORY}

The preceding analysis highlights possible reasons for observing seemingly aberrant estimates of cross-price elasticities among brands that conflict with an overall pattern of substitutability among the brands expected on a priori grounds. In particular, we single out

\footnotetext{
${ }^{3}$ Meta-analysis studies that review price elasticities have not always distinguished between market share elasticities and volume elasticities. It is well known that since an individual brand's Marshallian quantity demand elasticitiy is the sum of the market share elasticity and the primary demand elasticity (and the purchase incidence elasticity if one were to estimate this separately, see Gupta 1988), then the size of the primary demand elasticity may outweigh the market share elasticity - even in the case of the own-price elasticity. It is straightforward to show that this will occur in the same way for cross elasticities. Researchers often note that the primary demand component of a price elasticity is small relative to the market share component, typically citing results of Bell, Chiang and Padmanabhan (1999) or Van Heerde, Gupta and Wittink (2003).
} 
three patterns of anomalies where estimates of cross-elasticities depart from the expected pattern of substitution. First, we analyze conditions under which negative cross-elasticities may arise. Second, we consider when magnitude asymmetries can be expected among positive, sign-symmetric pairs of cross-elasticities. Finally, we discuss the case of sign asymmetric cross-elasticities. Using the Slutsky relation from Eqs. (8) through (10), we now formulate hypotheses identifying factors that predict the aforementioned phenomena.

\section{$\underline{\text { 3.1. Positive vs. Negative Signed Cross-Elasticities }}$}

As defined in (10), the second term, $R(i \& j)$, on the right-hand side of Eq. (13) is the Hicksian substitution between the two products. It must always to be positive since this measures the movement along a given indifference curve. Given that price and quantity must also always be positive, the first term on the right hand side of Eq. (13) is always positive and hence $E_{i j}^{*}$ in Eq. (16) must also always be positive.

Our initial hypothesis is related to the first term in the bracketed component of Eq. (16), the income elasticity of the focal brand $\left(I_{i}\right)$, weighted by the revenue share of the competing brand $\left(B_{j}\right)$. Since revenue share $\left(B_{j}\right)$ is always positive and income elasticity $\left(I_{i}\right)$ is typically positive (i.e., for superior goods), ceteris paribus, we expect that the greater the value of the product, $B_{j} \times I_{i}$, the more likely it is that $B_{j} \times I_{i}$ will be sufficiently positive to overcome the (positive) value of the first term in Eq. (16) containing the compensated price elasticity $\left(E^{*}{ }_{i j}\right)$ hence, the greater the likelihood that the sign of the cross-elasticity $\left(E_{i j}\right)$ will be negative. This may occur, for example, when the competing brand $(j)$ is superior, the focal brand $(i)$ is a large share brand and the two brands occupy distinct positions, such that the compensated substitution effect $(R(i \& j))$ is small. Thus, our first hypothesis becomes: 
H1: The larger the value of the product $\left(B_{j} I_{i}\right)$ of the revenue share of the competing brand $\left(B_{j}\right)$ and the income elasticity of the focal brand $\left(I_{i}\right)$, the greater the likelihood that the sign of the cross elasticity of the focal brand's (i) share with respect to the competing brand's $(j)$ price $\left(E_{i j}\right)$ is negative.

One caveat to this logic bears noting. It seems likely that the revenue shares of the competing $\left(B_{j}\right)$ and focal $\left(B_{i}\right)$ brands will be inversely related, since over all brands, shares must sum to one. If the competing brand's revenue share $\left(B_{j}\right)$ increases, the focal brand's revenue share $\left(B_{i}\right)$ may decrease. Especially in mature categories (or whenever category demand elasticity is close to zero), this means that the quantity sold of the focal brand $\left(q_{i}\right)$ decreases.

Since we expect category demand with respect to the price of the competing brand to be negative $\left(C_{j}<0\right)$, then the last term in Eq. (14) is positive and hence, ceteris paribus, the greater the competing brand's category expansion effect (a larger absolute value for $C_{j}$ ), the less likely it is that the cross-elasticity of the focal brand's share with respect to the competing brand's price $\left(E_{i j}\right)$ will be negative. Therefore, we state our second hypothesis as:

H2: The greater the absolute value of the elasticity of category demand with respect to the price of the competing brand $\left(C_{j}\right)$, the less the likelihood that the sign of the cross elasticity of the focal brand's (i) share with respect to the competing brand's $(j)$ price $\left(E_{i j}\right)$ is negative.

When would we expect this category expansion effect to be small? There is evidence that the price elasticity of category demand changes over the product life cycle (Hanssens, Parsons, and Schultz 2002, pp. 338-339). Specifically, the behavior of category price elasticity has been found to vary widely across categories according to stage of maturity and market structure (Nils, Dekimpe, Steenkamp,and Hanssens 2001). Multicategory comparisons of the primary demand effect reveal that the primary demand effect is 
often not significant. For example, Hoch, Kim, Montgomery, and Rossi (1996) found that average (across stores) category demand was inelastic in eleven of eighteen categories of food and non-food products sold in supermarkets. A common result is that the category demand effect for mature product categories is relatively small when compared with the share effect (see Bell, Chiang and Padmanabhan 1999; Van Heerde, Gupta and Wittink 2003). For similar reasons, the difference in the category demand elasticity for a pair of competing brands may also be expected to be small.

A third hypothesis we offer to help explain negative cross-price elasticities stems from the homogeneity condition (Eq. 7) requiring that the row sums of the substitution matrix must be equal to zero. As shown in Berndt and Silk (1993), this requirement is satisfied for the MCI model, but not for the MNL/ECI model. The logic behind the following hypothesis is found in the requirement that for any row in the matrix (5), the cross elasticity terms plus the own-elasticity must sum to zero.

To see the implications of this requirement, consider the following example with three brands, and the first row of the substitution matrix Eq. (5). Let $E_{11}$ be the own price elasticity and $E_{12}$ and $E_{13}$ be the cross-price elasticities for brand 1 with respect to the prices of brands 2 and 3 respectively. Then the closer the absolute value of $E_{11}$ divided by the maximum (positive) value of the cross-price elasticities is to zero, the greater the likelihood that a given cross-price elasticity is negative.

\section{H3: (MCI model only.) The smaller the absolute value of the focal brand's own-price elasticity, relative to the maximum value of its cross-price elasticities with respect to the other brands, the greater the likelihood that the cross-price elasticity is negative.}

Finally, we consider how the term in Eq. (14) involving the compensated

substitution rate, $E_{i j}^{*}$ (see Eq. (13)) might affect the sign of the cross elasticity, $E_{i j}$. Consider 
first the influence of the quantity of the focal brand $i, q_{i}$. The larger $q_{i}$, the more likely it is that $E_{i j}$ will be negative. To see this, note that since $R(i \& j)$ is positive and symmetric for the two brands, it follows that when $q_{i}$ is large then the influence of the compensated substitution rate is lower--i.e., the denominator of the first term in Eq. (14) increases. However, the latter effect may be offset by a fall in the budget share for the competing brand ( $\left.B_{j}\right)$, accompanying an increase in the budget share of the focal brand $i\left(B_{i}\right)$. Without further a priori insight into the association of an increase in quantity sold and the income elasticity (given by the shape of the Engel curve), we cannot draw conclusions on the directional impact of $q_{i}$ on the sign of the cross-price elasticity. Furthermore, except in industries that follow Cournot-style quantity setting behavior, quantity sold cannot be treated as exogenous. Given this ambiguity, we are unable to formulate a directional prediction concerning the influence of $q_{i}$. Therefore, we include this variable as a covariate in the analysis discussed below.

\section{$\underline{\text { 3.2 Pairwise Sign Asymmetric Cross-Elasticities }}$}

Lastly, we turn to sign asymmetries in pairs of cross elasticities. Here the Slutsky equation (see Eqs. 16 or 17) does not provide clear, a priori guidance as to what will cause the signs to be asymmetric, since such an outcome will depend on a set of complicated, nonlinear and implicit relationships governed by the functional forms of $E_{i j}$ and $E_{j i}$. Absent the necessary foundation for formulating hypotheses, we resort to conducting exploratory empirical analyses wherein we relate the presence of sign symmetry vs. sign asymmetry in pairs of cross-elasticities to the constructs represented on the right-hand side of Eq. (14). 


\section{DATABASE AND ESTIMATION OF MCI AND MNL SHARE MODELS}

We begin this section with a description of the database employed in our empirical analysis. Following that, we discuss the specification of the MCI and MNL/ECI share models used to estimate cross-elasticities. Lastly, we discuss the specification of the models used to estimate the income and category demand elasticities required to implement empirically tests of our hypotheses.

\subsection{Database}

The source of the data analyzed here is the Dominick's Finer Foods database, provided by the James M. Kilts Center, Graduate School of Business, University of Chicago. We investigate 127 brands from 25 sub-categories. The sub-categories are purposely selected so as to be composed of relatively homogeneous choice alternatives. That is, for each retailer category studied (laundry detergents, toilet tissue etc.) we identify subcategories within which we expect all brands should be highly substitutable. Table 4.1 provides a list and description of the sub-categories, including the number of brands in each sub category, as well as the number of store-weeks of data available.

\section{INSERT TABLE 4.1 HERE}

A total of 86 stores are in the Dominick's chain, and we have a maximum of 105 weeks of data available for any sub-category. In some sub-categories stockouts were observed, such that for given weeks the choice sets available to consumers were constrained. To avoid possible bias arising from these constrained choice sets, we use only the weeks and stores when the entire sub-category was available to consumers on the shelves. The data utilized includes measures of price per volume, price per unit, presence of promotions, and both quantity and unit sales. This approach may not capture dynamic or temporal effects of 
pricing and promotions, but we see this is as a missing observation problem and therefore leave that for future research.

An important issue is the choice of the set of substitutable items comprising each of the sub-categories. The phenomena of sign and magnitude asymmetries in cross elasticities may be rather trivial for a set of brands that were a priori complementary to one another (as an example, consider the subcategories pasta and pasta sauce). Thus, we restrict the scope of this research to market share attraction models for only substitutable items and choose categories where it is reasonable to assume that discrete choices are made within a category by a majority of consumers. As may be seen from Table 4.1, we consider, for example, different types of dishwashing detergent to be separate sub-categories, e.g., automatic dishwasher detergent and regular dishwashing detergent brands. For some categories, we also separate out the form of the product (e.g. liquid vs. powder), since households may purchase multiple forms for different use occasions. Often, there will be only one UPC at this level. Relating this discussion back to our earlier definition of the Hicksian compensated substitution effect, we select sub-categories in such a way that we are reasonably confident that the term $R(i \& j)>0$.

In order to minimize aggregation effects, we do not aggregate data across stores-in line with the finding in Christen, Gupta, Porter, Staelin, and Wittink (1997) that an aggregation bias arises in estimates for nonlinear models when sales data are summed across stores, and weighted average price of the UPCs are employed.

\subsection{Specification of MCI and MNL Share models}

We estimate own and cross elasticities for the fully-extended specifications for the MCI and MNL/ECI attraction models. Details on the derivation details and properties of the 
fully extended versions of the attraction models are discussed in Fok, Franses and Paap (2002). In attraction models of market response, market share for a brand depends on its attractiveness relative to the sum of the attractions of all competing brands (Bell, Keeney, and Little 1975). Attraction is specified as a function of a set of marketing mix variables and other covariates. For the fully extended model, each brand's attraction is related to a set of covariates for all brands, i.e.,

$$
\begin{array}{ll}
\text { MCI: } & A_{i t}=\exp \left(u_{i}+\varepsilon_{i t}\right) \prod_{j=1}^{m} \prod_{h=1}^{H} X_{h j t}^{\beta_{h j}} \\
\text { MNL/ECI: } & A_{i t}=\exp \left(u_{i}+\sum_{j=1}^{m} \sum_{h=1}^{H} \beta_{h j i} X_{h j t}+\varepsilon_{i t}\right)
\end{array}
$$

where $u_{i}$ is the intrinsic attractiveness for brand $i, x_{h j t}$ is the value for covariate $h$ for brand $j$ at time $t$ and $\beta_{h i j}$ are parameters relating the sensitivity of the attraction to changes in the covariate. The error component is $\varepsilon_{i t}$ and can take on a rich structure to accommodate a host of econometric issues (cf. Fok, Frances, and Paap 2002). The estimation procedure involves a "log-centering” linear transformation proposed by Cooper and Nakanishi (1988, pp. 28-29). ${ }^{4}$

The covariates in our model include retail price, in-store promotions and a number of seasonal and event-based indicator variables. After log-centering, the reduced form models for the MCI and MNL/ECI models, respectively, are:

MCI:

\footnotetext{
${ }^{4}$ The log-centering procedure applied to the fully extended model is possible because of the scale invariance of the geometric mean (or SIGM) property of attractions. This property is developed in Berndt and Silk (1993).
} 


$$
\begin{aligned}
& \ln \left(s_{c s i t} / \tilde{s}_{c s t}\right)=\alpha_{c i s}+\mu_{\mathrm{ciM}}+\mu_{\mathrm{cie}}+\sum_{\mathrm{l}=1}^{\mathrm{m}_{\mathrm{c}}-1} \lambda_{\text {cil }} \ln \left(\mathrm{s}_{\mathrm{csj}, \mathrm{t}-1}\right) \\
& +\sum_{\mathrm{j}=1}^{\mathrm{m}_{\mathrm{c}}} \beta_{i j c} \ln \left(X_{j c t}\right)+\sum_{j=1}^{m_{c}} \beta_{i j c}^{c} \ln \left(1+\{\mathrm{cpn}, \mathrm{bns}, \mathrm{pco}\}_{j c s t}\right)+\varepsilon_{c i s t}
\end{aligned}
$$

MNL/ECI:

$$
\begin{aligned}
& \ln \left(s_{c s i t} / \tilde{s}_{c s t}\right)=\alpha_{c i s}+\mu_{\mathrm{ciM}}+\mu_{\mathrm{cie}}+\sum_{\mathrm{l}=1}^{\mathrm{m}_{\mathrm{c}}-1} \lambda_{\text {cil }} \ln \mathrm{s}_{\mathrm{csi}, \mathrm{t}-1} \\
& +\lambda_{\mathrm{csi}} \mathrm{s}_{\mathrm{csi}, \mathrm{t}-1}+\sum_{j=1}^{m_{c}} \beta_{i j c} X_{j c t}+\sum_{j=1}^{m_{c}} \beta_{i j c}^{c}\{\mathrm{cpn}, \mathrm{bns}, \mathrm{pco}\}_{j c s t}+\varepsilon_{c i s t}
\end{aligned}
$$

where $c=$ category, $s=$ store, $M=$ month, $t=$ week, $m_{c}=$ number of brands in category $c$, $\{i, j\}=$ brand subscripts, $s_{c s i t}$ is brand $i$ 's share in $t, \widetilde{s}_{c s t}$ is the geometric mean of the shares of the brands in $c$ for $t, X_{c s i t}$ is the retail price for brand (consistent with our notational convention used throughout the paper), $s_{c s j, t-1}$ is lagged market share for brand $j$, and \{cpn,bns,pco $\}$ are metrics for promotions, i.e. coupon, bonus buy and a simple (promotional) price reduction, respectively. We originally coded promotions as dummy variables - a zero or one if a promotion is present for any UPC. The final promotion variable used in estimation is a weighted index of the promotions run across UPCs within a product line (e.g. Little 1998). The weights represent the share of the UPC for the brand over the entire observation series. Due to the narrow definition used for the categories studied, the number of UPCs per brand is often low and therefore the weighted promotional index is highly correlated with the non-weighted promotional variables. The components $\left(\mu_{c i M}+\mu_{c i e}\right)$ represent brand specific monthly and event-based unobserved variables.

For the MCI model, we then add a one to the promotion metric before taking logs, since this would otherwise require taking a log of zero for weeks/stores where no promotion was present. Because of the linear additive link function, the MNL/ECI model does not 
require us to add a one to the promotion variable. In both cases, the purpose of these covariates is to control for store-level promotional activities.

The other controls used in the market share specifications are mainly seasonal indicator variables. We use a rich set of variables to account for unobserved demand shocks. First, to account for unobserved monthly activities for these stores, we add in a set of monthly indicator variables. Second, we add in "event” based indicator variables. These events include major retailing chain-wide events that often have a considerable effect on store traffic. Examples of such events include Thanksgiving, Halloween, Easter, etc. . The presence of lagged responses is a common concern with sales models, although not so much with market share models. Nevertheless, the models include lagged market share terms for $m-1$ brands in each category.

For the empirical analysis, we use brand level data for each store and each week. We perform no aggregation across stores and weeks and minimal aggregation across SKUs. In estimating the parameters of Eq. (18), we constrain the estimates to be equal across stores and across weeks. While it is also valid to study micro-level parameters (e.g. see Montgomery 1997), our interest is more at the brand-market level (e.g. the Chicago DMA) than in identifying factors useful for fine-tuning the price structure at the store level. 


\section{$\underline{4.3 \text { Estimates of Cross-Price Elasticities }}$}

Price elasticities are calculated based on the estimated attraction coefficients $\left(\hat{\beta}_{i j}\right)$ for all brands competing against a focal brand. The elasticity expressions for the MCI and MNL models are given by (Cooper and Nakanishi 1988, pp. 144-145):

$$
\begin{array}{ll}
\text { MCI: } & \hat{E}_{i j}^{M C I}=\hat{\beta}_{i j}-\sum_{v=1}^{m} \bar{w}_{v} \hat{\beta}_{v j} \\
\text { MNL/ECI: } & \hat{E}_{i j}^{M N L}=\left(\hat{\beta}_{i j}-\sum_{v=1}^{m} \bar{w}_{v} \hat{\beta}_{v j}\right) \bar{X}_{j}
\end{array}
$$

where $\bar{w}_{v}$ is the mean market share for brand $v, \bar{X}_{j}$ is the mean value of retail price, and the "hat" above each value indicates that the parameter is estimated. The metrics $\left(\bar{w}_{v}, \bar{X}_{j}\right)$ are arithmetic means of the quantity market share across the 52 weeks and the arithmetic mean of the prices for the competing brands, also across the 52 weeks. A total of 732 cross-price elasticities were estimated for the 25 sub-categories listed in Table 4.1. The number of cross-elasticity estimates per sub-category depends on the number of brands available in a category, which varies from a minimum of 3 to a maximum of 12 . Note that the number of observations (stores $\times$ weeks) upon which the cross-elasticity estimates are based varies from a minimum of 3,910 to a maximum of 9,030 .

Table 4.1 also summarizes pertinent information about the signs of the MCI and MNL/ECI estimates. The relative incidence of negative-signed and sign-asymmetric crosselasticities is very similar for the MCI and MNL/ECI models, both in total and with respect to how these anomalies are distributed across the 25 sub-categories. Of the 732 crosselasticity estimates, $16.9 \%$ are negative for the MCI model and $17.8 \%$ for the MNL/ECI model. When the estimates are treated as pairs $(732 / 2=366)$, the percentage of sign 
asymmetric cross-elasticities is 40.7 and 43.7 for the MCI and MNL/ECI models, respectively. The proportion of the cross-elasticities within a category that are negative is quite stable across categories, being zero in seven of the 25 categories and ranging from $10 \%$ to $30 \%$ in the remainder. The incidence of sign asymmetric pairs is similarly stable across categories, again being zero in 7 of the 25 categories and varying from $4 \%$ to $10 \%$ of the pairs in the other categories.

Table 4.2 documents the distribution of the pairs of sign symmetric and sign asymmetric estimates according to their statistical significance, as judged by whether the ratio of the cross-elasticity estimate to its standard error was equal to or exceeded 2.0 in absolute value. Whereas for pairs of positive, sign symmetric cross-elasticities, both estimates are statistically significant for more than $60 \%$ of the pairs, such is the case for less than $30 \%$ of the negative, sign symmetric pairs, and for less than half of the sign asymmetric pairs. Again, the distributions of the MCI and MCI/ECI estimates are very similar with respect to statistical significance.

\section{INSERT TABLE 4.2 HERE}

\section{$\underline{4.4 \text { Estimation of Category Demand and Income Elasticities }}$}

A separate econometric model is estimated to obtain the category demand elasticities.

For each category we specify a log-log model for category demand ( $Q_{c s t}=\sum_{i=1}^{m_{c}} q_{c i s t}$ ) for each category $(c)$, brand $(i)$, store $(s)$ and week $(t)$ :

$$
\begin{aligned}
& \ln Q_{\mathrm{cst}}=\alpha_{c s}^{Q}+\mu_{c M}^{Q}+\mu_{c e}^{Q}+\lambda_{c}^{Q} \ln Q_{c s, t-1}+\delta_{c}^{Q} \ln \left(\bar{X}_{c s t}\right) \\
& +\sum_{j=1}^{m_{c}} \beta_{c i j}^{Q c} \ln \left(1+\{\mathrm{cpn}, \text { bns, pco }\}_{j c s t}\right)+\varepsilon_{c s t}^{Q}
\end{aligned}
$$


where $\bar{X}_{c s t}=\sum_{i=1}^{m_{c}} \bar{w}_{c i s} X_{c i s t}$ is a price index with expenditure share weights (constant over time) $\bar{w}_{c i s}$. The parameter $\delta_{c}^{Q}$ represents the category demand parameter with respect to the category price index and in fact is the estimated category demand elasticity. The category price elasticity for brand $i$ can be found by differentiating Eq. (20) with respect to the price (or $C_{i}=\partial \ln Q / \partial \ln X_{i}$ ).

In generating the income elasticity we had several choices for our metric of income. First, we could measure sensitivity of quantity demanded to actual income and measure using a survey-based demographic database, such as Consumer Expenditure Survey from the Bureau of Labor Statistics or the census. This is a common approach used in consumer demand theory (cf. Hausman, Leonard and Zona 1994, and Deaton and Muellbauer 1980). The problem with using available demographic data is the lack of temporal and crosscategory variance. While we expect an aggregate measure of income to affect the total amount spent on groceries within a year, we do not expect this variable to have much explanatory power for disaggregated subcategory choices. We therefore draw on the approaches used by past research (e.g., see Allenby and Rossi 1991b, and Deaton and Muellbauer 1980) and use the total amount spent on the subcategory as our metric for income. This income metric is also consistent with the definition of income $\left(X_{m+1}\right)$ in Appendix A.

The estimation equation used to generate income elasticities is a log-log quantity specification, controlling for prices and for other demand side shocks, and is also a function of the total category income: 


$$
\begin{aligned}
& \ln q_{c s i t}=\alpha_{c i s}^{q}+\mu_{c i M}^{q}+\mu_{c i e}^{q}+\lambda_{c s i}^{q} \ln q_{c s i, t-1}+\sum_{j=1}^{m_{c}} \beta_{c i j}^{q} \ln \left(X_{c s j t}\right) \\
& +\sum_{j=1}^{m_{c}} \beta_{c i j}^{q c} \ln \left(1+\{\mathrm{cpn}, \mathrm{bns}, \mathrm{pco}\}_{j c s t}\right)+\varphi_{c i}^{q} \ln \left(X_{m+1, c s t}\right)+\varepsilon_{c s i t}^{q}
\end{aligned}
$$

where $\alpha_{c i s}^{q}$ is the brand (and store) intercept, $\mu_{c i M}^{q}, \mu_{c i e}^{q}$ are month and event indicator variables, $q_{c s i, t-1}$ is the lagged quantity and $X_{m+1, c s t}$ is total expenditure on this category. For the log-log quantity model, the income elasticity for brand $i$ is directly given by the parameter, $\varphi_{c i}^{q}$.

\section{CROSS-CATEGORY ANALYSES OF ANOMALIES IN ESTIMATES OF CROSS-PRICE ELASTICITIES: HYPOTHESIS TESTS AND RESULTS}

We begin this section by defining measures of the explanatory variables used in the cross-category analyses to account for the types of anomalies in cross-price elasticities discussed above. We then outline the statistical models used in implementing the hypothesis tests and exploratory analysis related to each type of anomaly. Finally, we present our empirical findings.

\subsection{Definitions of Explanatory Variables}

We employ the following measures for the key constructs identified in the preceding analysis as factors influencing the sign and magnitude of cross-elasticities.

$B_{i}=\left(X_{i} q_{i}\right) / \sum_{j=1}^{m}\left(X_{j} q_{j}\right)=$ brand $i$ 's share of total category expenditures where each

$X_{i} q_{i}$ is a sum across stores and weeks;

$C_{i}=$ elasticity of category demand with respect to the price of focal brand $i$, estimated by the coefficient obtained when the natural logarithm of the total category

volume $\left(\ln \sum_{j=1}^{m} q_{j}\right)$ is regressed on the natural logarithm of the price of brand $i$ 
$\left(\ln X_{i}\right), C_{i} \leq 0$. See Eq. (20).

$I_{i}=$ elasticity of demand for brand $i$ with respect to total category expenditures, estimated by the coefficient obtained when the natural logarithm of quantity purchased of brand $i\left(\ln q_{i}\right)$ is regressed on the natural logarithm of total category expenditures $\left(\ln \sum_{j=1}^{m} X_{j} q_{j}\right), I_{i} \geq 0$. See Eq. (21).

$E_{i i}^{*}=E_{i i} / \max \left(E_{i j}\right)$, for all $j \neq i$, the ratio of the price elasticity of brand i's own-demand to the maximum (positive) value of its cross-price elasticities with respect to the other brands, $E^{*}{ }_{i i}<0$. $m_{c}=$ the number of brands in category $c, m_{c}>1$.

$C_{i}$ and $I_{i}$ are pooled (across stores and weeks) estimates from the category demand and quantity demand models, respectively, discussed earlier in Section 4.4. The variable $E^{*}{ }_{i i}$ is taken from the estimation of the MCI and MNL/ECI models. Both the number of brands $\left(m_{c}\right)$ and the budget shares $B_{i}$ are observed. Table B4.4 in the supplemental Appendix B presents summary statistics for the estimates values of the income elasticities (Median: 0.737, Std. Dev.: 0.346) and category demand elasticities (Median: -0.349, Std Dev.: 0.434) across the 127 brands marketed in the 25 product categories.

\subsection{Testing Hypotheses (H1-H3) Relating To Negatively vs. Positively Signed Cross Elasticities}

Hypotheses H1-H3 were derived from the Slutsky relation for the cross effect term, $E_{i j}$, per Eq. (14):

$$
E_{i j}=\left(X_{j} / q_{i}\right) R(i \& j)-\left(B_{j} I_{i}+C_{j}\right)<0
$$

We employ two distinct models in implementing tests of H1-H3. The first is a binary 
logit model specified as follows (the data is pooled across categories and each category is represented by $c$ ):

$$
\begin{aligned}
& \operatorname{Pr}\left(E_{i j}^{c}<0\right)=\exp \left(F^{c}\right) /\left(1+\exp \left(F^{c}\right)\right) \\
& F^{c}=\alpha^{c}+\sum_{c^{\prime}=1}^{C-1} \beta_{c^{\prime}} d_{c^{\prime}}+\lambda\left(X_{i}^{c} / q_{j}^{c}\right)+\tau m_{c}+\gamma B_{j}^{c}+\delta I_{i}^{c}+\phi B_{j}^{c} I_{i}^{c} \\
& +\eta C_{j}^{c}+\theta E_{i i}^{c^{*}}+\varepsilon_{i j}^{c}
\end{aligned}
$$

where $d_{c}$, are dummy variables for $C-1(C=6)$ categories comprising the cross-section of products listed in Table 4.1. Note that the dependent variable is defined as the probability that a cross-elasticity is negative, where the binary dependent variables used in the estimation was set equal to one if a cross-elasticity was negative $\left(E_{i j}^{c}<0\right)$, and zero, if positive. As may be seen from Table 4.1, 124 of the 732 (17 percent) cross-elasticity estimates for the MCI share model were negative while 130 of the 732 (18 percent) crosselasticity estimates for MNL/ECI share model were negative. The hypothesized relations discussed in Section 3.1 predict that:

$$
\text { H1: } \phi>0 ; \quad \text { H2: } \eta>0 ; \quad \text { H3: } \theta>0 \text {. }
$$

The first six variables on the RHS of Eq. (24) (the intercept, the set of category level dummies, the ratio of price of the $i$ th brand to quantity sold for the $j$ th brand, the number of brands in the category, and the main effects of budget share and income) serve as control variables for the (unobserved) Hicksian demand component, $(X / q) R(i \& j)$. An alternative way to capture the Hicksian demand component is, of course, to specify an intercept parameter for each pair of brands. However, no matter how many categories are studied, the number of parameters required to do so is extremely large, leading to numerical convergence problems and low degrees of freedom and power for testing hypotheses. 
Since the underlying dependent variable is continuous, we also tested H1-H3 based on a linear regression model, estimated via generalized least squares (GLS). The latter estimation adjusts for a possible lack of independence among the observations and facilitates correction for the presence of heteroskedasticity. ${ }^{5}$

$$
\begin{aligned}
E_{i j}^{c}=\alpha^{\prime} & +\sum_{c^{\prime}=1}^{C-1} \beta_{c^{\prime}}^{\prime} d_{c^{\prime}}+\lambda^{\prime}\left(X_{i}^{c} / q_{j}^{c}\right)+\tau^{\prime} m_{c}+\gamma^{\prime} B_{j}^{c} \\
& +\delta^{\prime} I_{j}^{c}+\phi^{\prime} B_{j}^{c} I_{i}^{c}+\eta^{\prime} C_{j}^{c}+\theta^{\prime} E_{i i}^{* c}+\varepsilon_{i j}^{c}
\end{aligned}
$$

Summary statistics for the variables specified in Eq. (24) are presented in the supplemental Appendix B, Table B5.1A1. From that table, it may be seen that although the means ( 0.521 and 0.062 ) and the standard deviations (1.253 and 0.135) of the MCI and MNL/ECI crosselasticity estimates, respectively, are quite different, the relative variability of the two sets of estimates is similar (coefficients of variation: 2.400 and 2.177, respectively). The two sets of cross-elasticity estimates are also fairly highly intercorrelated $(\mathrm{r}=0.667)$. The simple correlation between $E_{i j}$ and the binary dependent variable for the logit model is -0.636 for the MCI estimates and -0.407 for the MNL/ECI estimates. Note that the hypothesized signs of the coefficients for the relevant variables in Eq. (24) are the reverse of those for the binomial logit, i.e.,

H1: $\phi^{\prime}<0 ; \quad$ H2: $\eta^{\prime<0 ;}$ H3: $\theta^{\prime}<0$.

Parameter estimates for the binomial logit Eqs (22) and (23) and the regression model in Eq. (24) are presented in Table 5.1. In the case of the binomial logit results, H1 and

\footnotetext{
${ }^{5}$ Interdependence among a cross-section of observations of $E_{\mathrm{ij}}$ may arise here because for each brand, there is a set of cross-elasticities between that brand and all the other competing brands within the same category. To illustrate, for a category of 10 brands, there will 9 cross-elasticities for each brand. Bijmolt and Van Heerde (2001) make use of an iterative GLS method for multilevel or hierarchical models, due to Goldstein and Rashbash (1992), to account for such interdependencies. When we applied this procedure to the data in this study, tests indicated that the estimated within-group covariance was close to zero.
} 
$\mathrm{H} 2$ are supported by the estimated coefficients for $B_{j}^{c} I_{i}^{c}$ and $C_{i}^{c}$ respectively; the relevant coefficients for both the MCI and MNL/ECI estimates have the predicted signs and are statistically significant ( $p<0.01$, one-tail tests). However, H1 is supported by the GLS results for the MCI cross-elasticities but not for the MNL/ECI specifications, where the sign of estimated coefficient ( $\left.\phi^{\prime}\right)$ for $B_{j}^{c} I_{i}^{c}$ is the opposite of that predicted, albeit not statistically significant.

\section{INSERT TABLE 5.1 HERE}

The GLS results for both the MCI and MNL/ECI cross-elasticities are inconsistent with H2; the sign of the coefficient estimate $\left(\eta^{\prime}\right)$ for $C_{j}^{c}$ is positive, rather than negative as hypothesized (again, the estimate is not statistically significant). Diagnostic tests indicate that collinearity is not the source of the "wrong" signs here.

The results pertaining to $\mathrm{H} 3$ for the MCI cross-elasticities are also mixed. The estimated GLS coefficient $\left(\theta^{\prime}\right)$ for $E^{*}{ }_{i i}$ has the hypothesized sign and is statistically significant while that from the binomial logit $(\theta)$ is the opposite of that hypothesized (albeit again not statistically significant). Recall from the discussion in Section 3.1 that H3 is not applicable to the MNL/ECI model.

\subsection{Analysis of Pairwise Sign Asymmetric Cross-Elasticities}

Having obtained modest evidence in support of our three principal hypotheses, we now consider empirical findings for those situations in which theory did not provide unambiguous predictions. As a point of departure for the exploratory analyses of sign asymmetries, consider the difference between a matched pair of cross-elasticities: 


$$
E_{j i}-E_{i j}=\frac{X_{i} q_{i}-X_{j} q_{j}}{q_{i} q_{j}} R(i \& j)+\left(-B_{i} I_{j}+B_{j} I_{i}\right)+\left(C_{j}-C_{i}\right)
$$

An exploratory analysis of possible factors influencing sign asymmetry between pairs of cross-elasticities was conducted again using both a binary logit and a linear regression model. For the logit model, the dependent variable is the probability that both members of a pair of cross-elasticities have the same, rather than opposite signs.

$$
\begin{gathered}
\operatorname{Pr}\left(E_{j i}^{c} \& E_{i j}^{c} \text { Sign Symmetric }\right)=\exp \left(K^{c}\right) /\left(1+\exp \left(K^{c}\right)\right) \\
\begin{aligned}
K^{c}=\alpha & +\sum_{c^{\prime}=1}^{c-1} \beta_{c^{\prime}} d_{c^{\prime}}+\lambda\left(\Delta X^{c} q^{c}\right) /\left(q_{i}^{c} q_{j}^{c}\right)+\tau m_{c}+\gamma D_{1}\left(\Delta B^{c}\right) \\
& +\delta D_{2}\left(\Delta I^{c}\right)+\phi D_{3}\left(\Delta B^{c} I^{c}\right)+\eta D_{4}\left(\Delta C^{c}\right)+\varepsilon_{j i}^{c}
\end{aligned}
\end{gathered}
$$

Included as control variables are dummy variables $\left(d_{c^{\prime}}\right)$ for $C-1$ sub-categories, the term $\Delta\left(X^{c} q^{c}\right) /\left(q_{i}^{c} q_{j}^{c}\right) \equiv\left\{X_{i}^{c} q_{i}^{c}-X_{j}^{c} q_{j}^{c}\right\} /\left(q_{i}^{c} q_{j}^{c}\right)$ that interacts with the unobservable Hicksian component $R(i \& j)$ in Eq. (17), and the number of brands $\left(m_{c}\right)$. The other four binary variables on the right-hand side of Eq. (27) are defined as follows:

$$
\begin{aligned}
& D_{1}\left(\Delta B^{c}\right)=1 \text {, if } B_{j}^{c}>B_{i}^{c} ;=0 \text {, otherwise. } \\
& D_{2}\left(\Delta I^{c}\right)=1 \text {, if }\left(I_{i}^{c}>I_{j}^{c}\right) ;=0 \text {, otherwise. } \\
& D_{3}\left(\Delta B^{c} I^{c}\right)=1 \text {, if }\left(B_{j}^{c} I_{i}^{c}>B_{i}^{c} I_{j}^{c}\right) ;=0 \text {, otherwise. } \\
& D_{4}\left(\Delta C^{c}\right)=1 \text {, if }\left(C_{j}^{c}>C_{i}^{c}\right),=0 \text {, otherwise. }
\end{aligned}
$$

The binary dependent variable employed in estimating Eq. (26) was defined as: $D(S S)=1$ if $E_{j i}^{c}$ and $E_{i j}^{c}$ have the same sign; = 0, if the pair is sign asymmetric. 
As may be seen from Table 4.1, for the 366 pairs of cross-elasticities estimated for each share model, sign symmetry was observed for 59 percent (217) of the MCI estimates and for 56 percent (206) of the MNL/ECI estimates.

Parallel to the structure of the binary logit model in Eqs. (26) and (27), the following linear regression model was also estimated by means of GLS, where here the dependent variable and regressors are continuous, rather than binary as in the logit model.

$$
\begin{aligned}
\Delta E^{c} \equiv E_{j i}^{c}-E_{i j}^{c}= & \alpha^{\prime}+\sum_{c^{\prime}=1}^{C-1} \beta_{c}{ }^{\prime} d_{c}+\lambda^{\prime}\left(\Delta X^{c} q^{c}\right) /\left(q_{i}^{c} q_{j}^{c}\right)+\tau^{\prime} m_{c}+\gamma^{\prime}\left(\Delta B^{c}\right) \\
& +\delta^{\prime}\left(\Delta I^{c}\right)+\eta^{\prime}\left(\Delta C^{c}\right)+\varepsilon_{i}^{c \prime}
\end{aligned}
$$

Summary statistics for the explanatory variables included in the binary logit and regression models are presented in the supplemental Appendix B, Tables B5.2A1-B5.2B3. Parameter estimates for binomial logit Eqs. (26) and (27) and regression model Eq. (28) are given in Table 5.2 .

Overall, the exploratory analysis conducted using these two models failed to reveal any covariates that were consistently associated with sign asymmetry in MCI and MNL/ECI cross-elasticity estimates. While the signs of the estimated coefficients for the covariates obtained for the MCI cross-elasticities tended to be consistent with those for the MNL/ECI for each of the logit and regression models, the signs were not consistent across models. Moreover, the covariates that appeared to be statistically significant in the binomial logit model tended to be different from those significant in the regression model.

\section{INSERT TABLE 5.2 HERE}

\subsection{Summary of Hypothesis Test Results}

We summarize results of the various tests of our hypotheses discussed above in Table 5.3. Confirming evidence for $\mathrm{H} 1$ was obtained in three of the four tests. The tests for 
H2 were supported by the binomial logit model but not supported by the regression models. H3 (MCI only) was only supported by the results from the regression models. Whereas the binomial logit model produced hypothesis test outcomes that are qualitatively similar for both the MCI and the MNL/ECI cross-elasticity estimates, the regression model test results for MCI and MNL/ECI were equally split between agreeing with respect to confirming H2 and conflicting with respect to support vs. rejection of H1.

\section{INSERT TABLE 5.3HERE}

If the binomial logit results are discounted on grounds of being subject to possible threats arising from heteroskedasticity and non-independence of the underlying observations, then greater reliance should be placed on tests arising from the regression model where adjustments were made to address those issues. Doing so, one is led to conclude that with the exception of H2, all the hypotheses obtain support from the tests conducted with MCI cross-elasticities. More specifically, the GLS estimates of the regression model for MCI and MNL/ECI are concordant with respect to H2 (disconfirmation), but discordant with respect to $\mathrm{H} 1$; recall that $\mathrm{H} 3$ is applicable only to the MCI cross-elasticities. As was pointed out earlier, the correlation between the MCI and MNL/ECI cross-elasticities is substantial and their coefficients of variation are of similar magnitude. The data for the regressors in the MCI and MNL/ECI models used to test $\mathrm{H} 1$ are identical. Hence, at this point we are unable to account for the conflicting results obtained with respect to the latter pair of hypotheses.

\section{DISCUSSION}

Market share models are commonly used to measure market level substitution patterns. A troubling issue encountered in such studies is that seemingly anomalous results 
can and do arise. As Montgomery and Rossi (1999) observed: "Unrestricted least squares estimates of own and cross-price elasticities are often of an incorrect sign and unreasonable magnitude, particularly if the analysis is performed at a relatively low level of aggregation, such as the account or store level” (p. 413). This paper advances understanding of such troubling observed anomalies in two ways.

First, we demonstrate that the presence of negative cross-elasticities is at least theoretically possible and can be explained by the relative magnitudes of the share-weighted income elasticity, the unobserved Hicksian compensated rate of substitution, and the category demand effect. Second, we further show that asymmetries in the signs for adjacent pairs of cross elasticities are also theoretically possible and explicable in the same way. This latter finding implies that it is possible for a pair of brands to be simultaneously a substitute and a complement to one another.

The value of these theoretical insights in large measure depends upon the extent to which the aberrant effects addressed occur in empirical work. Using market share attraction models, we estimated cross-elasticities for 25 categories of consumer packaged goods, involving a total of 127 brands. Our findings reveal that among the 732 cross elasticities estimated, about $17-18 \%$ are negative. In only seven of the 25 categories were all the estimated cross elasticities positive. In light of this incidence of negative signs, it is not surprising that in about $40 \%$ of the 366 pairs of cross-elasticities, the estimates were asymmetric with respect to sign.

Our theoretical analysis of the Slutsky equation led to the formulation a set of hypotheses that could account for the occurrence of negatively-signed cross-elasticity between a pair of brands that are substitutes in the sense that the unobserved Hicksian 
compensated price elasticity is positive. As summarized in Table 5.3, some empirical support was found for each of our three hypotheses. In the case of pairwise sign asymmetric cross elasticities, we concluded that the Slutsky equation was of little help in predicting the phenomenon of sign asymmetry. Instead, we undertook an exploratory analysis in search of empirical regularities but found none, as our theoretical analysis had suggested.

\subsection{Implications}

Given these findings, what advice can we offer? Rather than dismissing negative cross-elasticity estimates out of hand, we propose that investigators assess whether they can be explained by the combination of an income effect, substitution effect and the category demand effect, as indicated by H1-H3. Drawing on the elasticity estimates from this study, we illustrate the usefulness of such additional analyses. For example, in the case of the powdered laundry detergent category, we find a negative cross elasticity of -0.45 for Tide with respect to the price of Oxydol (both, incidentally, P\&G brands). Although Oxydol has a revenue share of approximately $10 \%$, Tide has a relatively large income elasticity of around 1.1. Moreover, the elasticity of Oxydol's price changes on category demand is -0.31 . These effects work in combination to produce a negative cross elasticity for Tide with respect to Oxydol.

Analysis of the antecedents of asymmetries in cross-price elasticities identified in this study can also be useful to assist managers in understanding key properties of a brand's competitive position such as its clout and vulnerability. A focal brand is said to be vulnerable when the cross elasticity of the focal brand with respect to some action taken by a competing brand is high and positive. A positive cross-elasticity reflects vulnerability in the sense that it is measures how much share that a competing brand's price changes can draw 
from the focal brand. Clout is the converse of vulnerability; viewed in terms of the substitution matrix, it is the opposite diagonal, and represents how much share that the focal brand can draw from the competitor.

While more complex methods are available (cf. Cooper and Nakanishi, 1988, Chapt. 6 and Kamakura and Russell, 1989), a simple 2 by 2 contingency table analysis will serve to illustrate how determinants of asymmetric cross-price elasticities affect a brand's clout and vulnerability. First, assume that the two brands are approximately symmetric with respect to their compensated cross-elasticities. Second, assume that there is no category expansion effect of price (i.e. in Eq. 14, $\mathrm{C}_{\mathrm{i}}=0$ ). The two remaining dimensions are the income elasticity of the focal brand and the expenditure share value of the competing brand. Extending the previous example of Tide competing against Oxydol, we identify low and high vulnerability regions as follows:

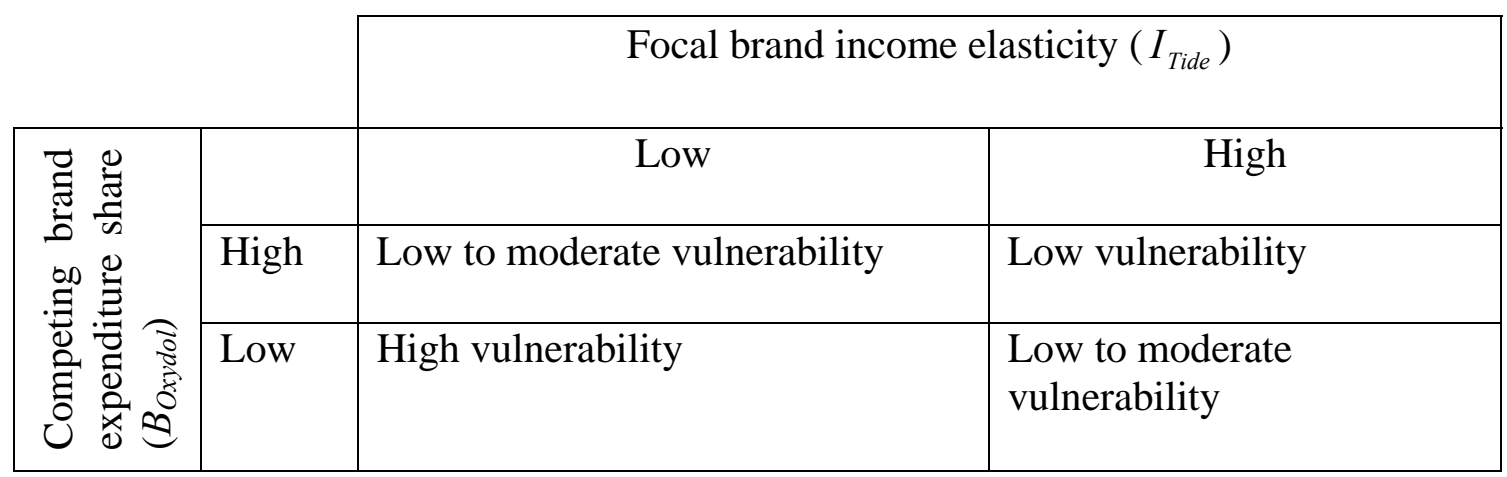

We conjecture that the special case of negative cross-elasticities is most likely to arise in the upper right hand quadrant, where the focal brand, Tide, enjoys such low vulnerability that the competing Oxydol brand turns out to be complementary to Tide. This illustration highlights that an understanding of the antecedents of cross-elasticities can be useful in diagnosing the level of clout and vulnerability a brand may possess. Development 
of a more general taxonomy of the factors underlying clout and vulnerability is beyond the primary focus of the present paper, negative cross-elasticities.

The kind of informal analysis outlined above appears broadly consistent with Montgomery and Rossi's (1999) position that while restrictions from economic theory should not be expected to hold exactly in practice, they do nevertheless represent useful source of prior information from which the analyst should draw.

\subsection{Limitations and Directions for Further Research}

Several limitations and directions for further research deserve to be mentioned. First, we acknowledge that we are able to report only partial support for our hypotheses. At least in part, this may be due to the intrinsic non-linearity that is inherent among the set of variables used to test these hypotheses. For example, it is likely that a change in expenditure share also affects a change in the compensated price elasticity because both make use of the quantity variable. Of course, it is also the case that absence of evidence is not the same as evidence of absence. Thus, even though the hypothesized relationships may be correct, the empirical implementation may not have been adequate to identify and reliably quantify the relationships.

Second, our theoretical results hold for any quantity market share response model. However, our empirical study considered only two types of fully extended attraction models. This leaves open the important question of what are the properties of other types of market share response models that are also used to measure substitution patterns, such as random

coefficient logit models (e.g. Besanko, Gupta and Jain 1998, Nevo 2001), classic demand models such as log-log quantity models (cf. Christen, Gupta, Porter, Staelin and Wittink 1997, Montgomery and Rossi 1999) or aggregate probit models (cf. Chintagunta 2001). 
Third, the implications of our results for models in the new empirical industrial organization literature merit consideration (Kadiyali, Sudhir, and Rao 2001). Since some cross elasticities in a substitution matrix may be negative, how does this condition affect the measurement and analysis of competitive structure? A negative cross elasticity between two competing brands implies that the two brands are complementary in purchases. Our paper shows that these results are not necessarily invalid. The presence of negative cross elasticities may, however, yield some counter-intuitive interrelationships among competitors. The implications for equilibrium analysis of substitution matrices that include negative cross elasticities should be investigated.

\section{CONCLUSIONS}

Researchers often examine empirical findings with respect to their "face validity." Judgments about face validity are generally grounded in some theoretical insights about what result should be expected/unexpected and/or what is plausible/implausible. In this paper, we have emphasized the properties of homogeneity and symmetry from neoclassical demand theory as desiderata for estimates of cross-elasticities. While asymmetry is generally accepted as an inherent property of a substitution matrix, our results demonstrate that both negative signs and sign asymmetry in substitution patterns are theoretically possible. These theoretical insights were empirically verified with market data. Our analyses suggest that almost one in five of the cross elasticities are negative. For only seven out of the 25 categories studied did we find all cross elasticities to be positive. Asymmetric signs across pairs of cross elasticities occurred about $40 \%$ of the time. While we have reported a substantial amount of progress in developing a theoretical understanding of the conditions under which negative and sign asymmetric cross-elasticities can occur, more 
needs to be done to better predict when they are likely to occur, and in such situations, how to interpret them. 
Figure 1: A graphic illustration of the difference between compensated and uncompensated substitutions for Tide liquid laundry detergents versus Wisk liquid laundry detergents. A decrease in the price for Wisk leads to an outward shift in the budget constraint from $I_{0}$ to $I_{1}$.

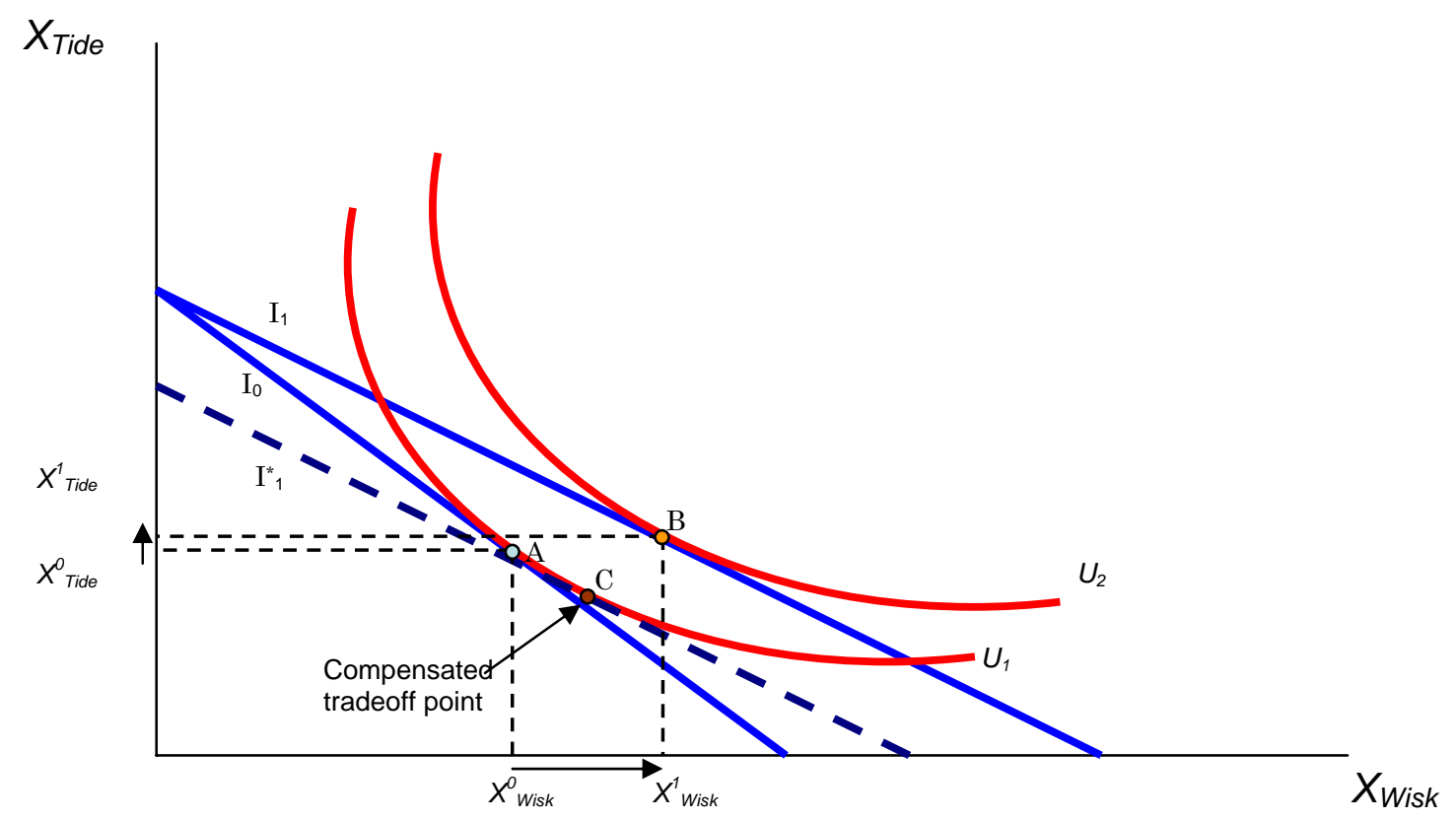


Table 4.1

DESCRIPTIONS OF CATEGORIES AND SUB-CATEGORIES AND COUNTS Of CROSS ELASTICITY ANOMALIES

\begin{tabular}{|c|c|c|c|c|c|c|c|}
\hline Category/Sub-Category & $\begin{array}{l}\text { Number } \\
\text { Brands }\end{array}$ & $\begin{array}{l}\text { Number } \\
\text { Observ. }\end{array}$ & $\begin{array}{l}\text { No. Cross- } \\
\text { Elasticities }\end{array}$ & $\begin{array}{c}\text { MCI } \\
\text { Neg. } \\
\text { Sign } \\
\text { Cross } \\
\text { Elas. }\end{array}$ & $\begin{array}{l}\text { MCI } \\
\text { Sign } \\
\text { Asymm. } \\
\text { Pairs }\end{array}$ & $\begin{array}{l}\text { MNL } \\
\text { Neg. } \\
\text { Sign } \\
\text { Cross } \\
\text { Elas. }\end{array}$ & $\begin{array}{l}\text { MNL } \\
\text { Sign } \\
\text { Asym. } \\
\text { Pairs }\end{array}$ \\
\hline $\begin{array}{l}\text { Pain Relievers } \\
\text { - } \quad 24 \text { Tablets } \\
\text { - } \quad 50 \text { Tablets } \\
\text { - } \quad \text { 100Tablets }\end{array}$ & $\begin{array}{l}3 \\
4 \\
3\end{array}$ & $\begin{array}{l}8,925 \\
7,480 \\
9,030\end{array}$ & $\begin{array}{c}6 \\
12 \\
6\end{array}$ & $\begin{array}{l}0 / 6^{\mathrm{a}} \\
0 / 12 \\
0 / 6\end{array}$ & $\begin{array}{l}0 / 3^{b} \\
1 / 6 \\
0 / 3\end{array}$ & $\begin{array}{l}0 / 6^{\mathrm{a}} \\
0 / 12 \\
0 / 6\end{array}$ & $\begin{array}{l}0 / 3^{b} \\
1 / 6 \\
0 / 3\end{array}$ \\
\hline Toothbrushes & 4 & 9,030 & 12 & $0 / 12$ & $0 / 6$ & $0 / 12$ & $0 / 6$ \\
\hline $\begin{array}{l}\text { Dishwashing Detergents } \\
\text { - } \quad \text { Automatic Liquid,50 oz. } \\
\text { - } \quad \text { Automatic Liquid, } 65 \mathrm{oz} . \\
\text { - } \quad \text { Automatic Powder, } 50 \mathrm{oz} . \\
\text { - } \quad \text { Automatic Powder, } 65 \mathrm{oz} . \\
\text { - } \quad \text { Regular, } 12 \mathrm{oz} . \\
\text { - } \quad \text { Regular, } 22 \mathrm{oz} . \\
\text { - } \quad \text { Regular, } 32 \mathrm{oz} . \\
\text { - } \quad \text { Regular, } 42 \mathrm{oz} .\end{array}$ & $\begin{array}{l}2 \\
3 \\
4 \\
5 \\
4 \\
8 \\
8 \\
4\end{array}$ & $\begin{array}{l}9,030 \\
9,030 \\
9,030 \\
9,030 \\
9030 \\
9,030 \\
9,030 \\
7,396\end{array}$ & $\begin{array}{c}2 \\
6 \\
12 \\
20 \\
12 \\
56 \\
56 \\
12\end{array}$ & $\begin{array}{l}0 / 2 \\
2 / 6 \\
2 / 12 \\
7 / 20 \\
2 / 12 \\
10 / 56 \\
10 / 56 \\
1 / 12\end{array}$ & $\begin{array}{c}0 / 1 \\
0 / 3 \\
3 / 6 \\
6 / 10 \\
1 / 6 \\
11 / 28 \\
11 / 28 \\
2 / 6\end{array}$ & $\begin{array}{l}0 / 2 \\
1 / 6 \\
2 / 12 \\
7 / 20 \\
2 / 12 \\
12 / 56 \\
12 / 56 \\
1 / 12\end{array}$ & $\begin{array}{l}0 / 1 \\
0 / 3 \\
4 / 6 \\
5 / 20 \\
1 / 6 \\
14 / 28 \\
14 / 28 \\
1 / 6\end{array}$ \\
\hline $\begin{array}{l}\text { Laundry Detergents } \\
\text { - } \quad \text { Liquid, } 64 \mathrm{oz} . \\
\text { - } \quad \text { Liquid, } 96 \mathrm{oz} . \\
\text { - } \quad \text { Liquid, } 128 \mathrm{oz} . \\
\text { - } \quad \text { Powder, } 42 \mathrm{oz} . \\
\text { - } \quad \text { Powder, } 70 \mathrm{oz} . \\
\text { - } \quad \text { Powder, } 98 \mathrm{oz} . \\
\text { - } \quad \text { Powder, } 136 \mathrm{oz} .\end{array}$ & $\begin{array}{c}12 \\
8 \\
11 \\
5 \\
3 \\
3 \\
3\end{array}$ & $\begin{array}{l}6,120 \\
6,545 \\
7,565 \\
3,910 \\
4,956 \\
7,482 \\
4,956\end{array}$ & $\begin{array}{r}132 \\
56 \\
110 \\
20 \\
6 \\
6 \\
6\end{array}$ & $\begin{array}{c}18 / 132 \\
6 / 56 \\
26 / 110 \\
1 / 20 \\
1 / 6 \\
1 / 6 \\
1 / 6\end{array}$ & $\begin{array}{c}37 / 66 \\
9 / 28 \\
25 / 55 \\
2 / 10 \\
1 / 3 \\
1 / 3 \\
1 / 3\end{array}$ & $\begin{array}{l}20 / 132 \\
7 / 56 \\
25 / 110 \\
1 / 20 \\
1 / 6 \\
1 / 6 \\
1 / 6\end{array}$ & $\begin{array}{l}36 / 132 \\
12 / 56 \\
24 / 55 \\
2 / 10 \\
2 / 3 \\
1 / 3 \\
2 / 3\end{array}$ \\
\hline $\begin{array}{l}\text { Paper Towels } \\
\text { - } \quad 1 \text { Roll } \\
\text { - } \quad 3 \text { Rolls }\end{array}$ & $\begin{array}{r}10 \\
4\end{array}$ & $\begin{array}{l}9,030 \\
8,944\end{array}$ & $\begin{array}{l}90 \\
12\end{array}$ & $\begin{array}{r}22 / 90 \\
1 / 12\end{array}$ & $\begin{array}{c}20 / 45 \\
1 / 6\end{array}$ & $\begin{array}{r}22 / 90 \\
1 / 12\end{array}$ & $\begin{array}{c}21 / 45 \\
1 / 6\end{array}$ \\
\hline \begin{tabular}{ll}
\multicolumn{2}{l}{ Toilet Tissue } \\
- & 4 Rolls \\
- & 6 Rolls \\
- & 9 Rolls \\
- & 12 Rolls
\end{tabular} & $\begin{array}{l}9 \\
3 \\
2 \\
2\end{array}$ & $\begin{array}{l}6,708 \\
7,480 \\
4,165 \\
9,030\end{array}$ & $\begin{array}{r}72 \\
6 \\
2 \\
2\end{array}$ & $\begin{array}{c}12 / 72 \\
1 / 6 \\
0 / 2 \\
0 / 2\end{array}$ & $\begin{array}{c}16 / 36 \\
1 / 3 \\
0 / 1 \\
0 / 1\end{array}$ & $\begin{array}{c}13 / 72 \\
1 / 6 \\
0 / 2 \\
0 / 2\end{array}$ & $\begin{array}{c}18 / 36 \\
1 / 3 \\
0 / 1 \\
0 / 1\end{array}$ \\
\hline TOTAL: 25 & & & 732 & $124 / 732$ & $149 / 366$ & $130 / 732$ & $160 / 366$ \\
\hline
\end{tabular}

${ }^{\text {a }}$ Read: zero of 6 cross-elasticities have negative signs.

b Read: zero of 3 pairs of cross-elasticities are sign asymmetric. 
Table 4.2

SUMMARY OF SIGN AND STATISTICAL SIGNIFICANCE OF 366 PAIRS OF CROSSPRICE ELASTICITY ESTIMATES FROM 25 SUB-CATEGORIES*

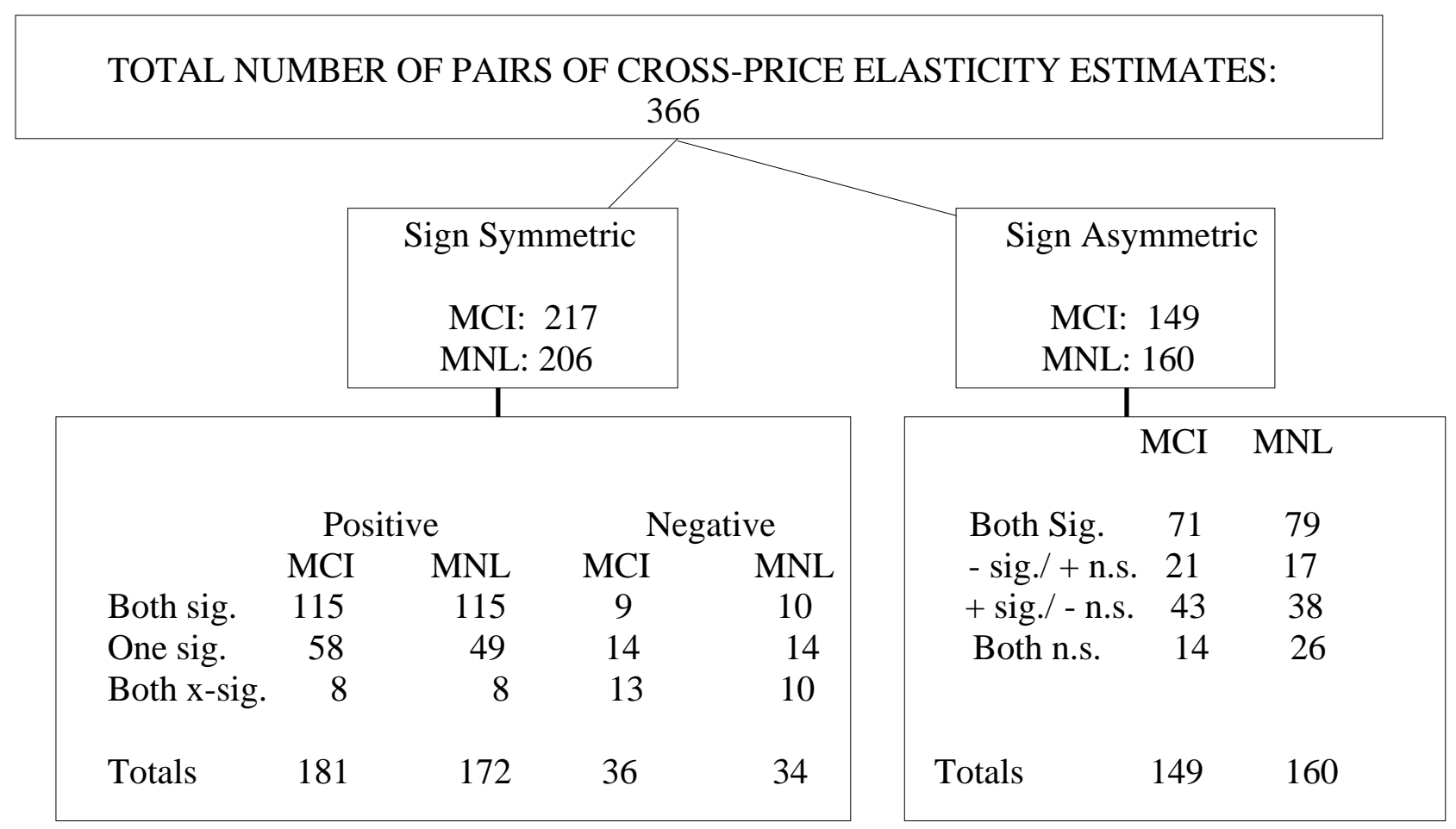

* Statistical significance for a cross elasticity is evaluated using a two tailed t-test with $\mathrm{p}=0.05$. 
Table 5.1

TESTS OF HYPOTHESES H1-H3

Estimated Coefficients

(Ratio of Coefficient to Standard Error)

\begin{tabular}{|c|c|c|c|c|c|}
\hline & \multicolumn{2}{|c|}{ Binomial Logit ${ }^{1}$} & \multicolumn{3}{|c|}{ Generalized Least Squares $^{2}$} \\
\hline $\begin{array}{l}\text { Dependent } \\
\text { Variable }\end{array}$ & \multicolumn{2}{|c|}{$\operatorname{Pr}\left(E_{i j}<0\right)$} & \multicolumn{3}{|c|}{$E_{i j}$} \\
\hline Variable & MCI & MNL & Variable & MCI & MNL \\
\hline$B_{j}$ & $\begin{array}{l}-15.423 \\
(5.835)\end{array}$ & $\begin{array}{l}-16.021 \\
(5.820)\end{array}$ & $B_{j}$ & $\begin{array}{l}5.381 \\
(7.725)\end{array}$ & $\begin{array}{c}0.212 \\
(7.019)\end{array}$ \\
\hline$I_{i}$ & $\begin{array}{l}-0.979 \\
(1.882)\end{array}$ & $\begin{array}{l}-0.923 \\
(1.810)\end{array}$ & $I_{i}$ & $\begin{array}{c}0.326 \\
(1.422) \\
\end{array}$ & $\begin{array}{c}0.003 \\
(0.678) \\
\end{array}$ \\
\hline $\begin{array}{l}B_{j}^{*} I_{i} \\
\mathbf{H 1}\end{array}$ & $\begin{array}{c}9.999^{c} \\
(2.815)\end{array}$ & $\begin{array}{c}9.620^{\mathrm{c}} \\
(2.627)\end{array}$ & $\begin{array}{l}B_{j} * I_{i} \\
\text { H1 }\end{array}$ & $\begin{array}{l}-2.010^{\mathbf{b}} \\
(1.735)\end{array}$ & $\begin{array}{c}0.009 \\
(0.203)\end{array}$ \\
\hline $\begin{array}{l}C_{j} \\
\mathbf{H} 2\end{array}$ & $\begin{array}{c}0.574^{\mathrm{C}} \\
(3.143)\end{array}$ & $\begin{array}{c}0.337^{\mathbf{b}} \\
(2.122)\end{array}$ & $\begin{array}{l}C_{j} \\
\mathbf{H} 2\end{array}$ & $\begin{array}{l}0.004 \\
(0.079\end{array}$ & $\begin{array}{c}0.002 \\
(1.837)\end{array}$ \\
\hline $\begin{array}{l}E_{i i}^{*} \\
\mathbf{H 3}\end{array}$ & $\begin{array}{l}-0.022 \\
(0.131)\end{array}$ & n.a. & $\begin{array}{l}E_{i i}^{*} \\
\text { H3 }\end{array}$ & $\begin{array}{l}-0.159^{c} \\
(2.430)\end{array}$ & n.a. \\
\hline$X_{j} / q_{i}$ & $\begin{array}{l}-0.155 \\
(0.532)\end{array}$ & $\begin{array}{c}1.099 \\
(3.480)\end{array}$ & $X_{j} / q_{i}$ & $\begin{array}{l}-0.058 \\
(0.922)\end{array}$ & $\begin{array}{r}-0.008 \\
(3.370) \\
\end{array}$ \\
\hline$m_{c}$ & $\begin{array}{l}-0.080 \\
(1.333)\end{array}$ & $\begin{array}{c}-0.076 \\
(1.536)\end{array}$ & $m_{c}$ & $\begin{array}{l}0.018 \\
(0.817)\end{array}$ & $\begin{array}{c}0.001 \\
(1.549)\end{array}$ \\
\hline $\begin{array}{l}\text { Category } \\
\text { Dummy } \\
\text { Variables }\end{array}$ & 1 sig. & 1 sig. & $\begin{array}{l}\text { Category } \\
\text { Dummy } \\
\text { Variables }\end{array}$ & None & 1 Sig. \\
\hline Intercept & $\begin{array}{l}1.306 \\
(2.000)\end{array}$ & $\begin{array}{l}1.419 \\
(2.321) \\
\end{array}$ & Intercept & $\begin{array}{l}0.584 \\
(2.372) \\
\end{array}$ & $\begin{array}{l}-0.008 \\
(1.147) \\
\end{array}$ \\
\hline Log Likelihood & -390.791 & -392.562 & S.E.E. & 1.103 & 0.125 \\
\hline McFadden $\mathrm{R}^{2}$ & 0.128 & 0.135 & $\mathrm{R}^{2}$ (adj.) & 0.225 & 0.136 \\
\hline $\begin{array}{l}\text { Percent } \\
\text { Correctly } \\
\text { Classified } \\
\end{array}$ & 70.63 & 69.95 & & n.a. & n.a. \\
\hline
\end{tabular}

${ }^{\mathrm{a}} \mathrm{p}<0.10 \quad{ }^{\mathrm{b}} \mathrm{p}<0.05 \quad{ }^{\mathrm{c}} \mathrm{p}<0.01$ one tail tests, $\mathrm{n}=732$.

${ }^{1}$ Robust standard errors computed using quasi-maximum likelihood methods.

${ }^{2}$ White heteroskedasticity-consistent standard errors and covariances. 
Table 5.2

ANALYSES OF SIGN-ASYMMETRIC CROSS ELASTICITIES

Estimated Coefficients

(Ratio of Coefficient to Standard Error)

\begin{tabular}{|c|c|c|c|c|c|}
\hline & \multicolumn{2}{|c|}{ Binomial Logit ${ }^{1}$} & \multicolumn{3}{|c|}{ Generalized Least Squares $^{2}$} \\
\hline $\begin{array}{l}\text { Dependent } \\
\text { Variable }\end{array}$ & \multicolumn{2}{|c|}{$\begin{array}{l}\operatorname{Pr}\left(E_{i j} \& E_{j i}\right. \\
\text { Sign Sym. })\end{array}$} & \multicolumn{3}{|c|}{$\left(E_{i j}-E_{j i}\right)$} \\
\hline Variable & MCI & MNL & Variable & MCI & MNL \\
\hline$D_{l}(\Delta B)$ & $\begin{array}{l}-0.860^{\mathbf{b}} \\
(2.431)\end{array}$ & $\begin{array}{l}-0.520^{b} \\
(1.534)\end{array}$ & $\Delta B$ & $\begin{array}{l}-0.837 \\
(0.371)\end{array}$ & $\begin{array}{l}-0.162 \\
(1.264)\end{array}$ \\
\hline$D_{2}(\Delta I)$ & $\begin{array}{l}-0.768^{b} \\
(2.368)\end{array}$ & $\begin{array}{l}-0.466^{\mathbf{b}} \\
(1.519)\end{array}$ & $\Delta I$ & $\begin{array}{l}0.103 \\
(0.183)\end{array}$ & $\begin{array}{c}0.015 \\
(0.509)\end{array}$ \\
\hline$D_{3}(\triangle B I)$ & $\begin{array}{l}0.251 \\
(0.971) \\
\end{array}$ & $\begin{array}{l}0.152 \\
(0.596)\end{array}$ & $\Delta B I$ & $\begin{array}{l}-0587 \\
(0.216)\end{array}$ & $\begin{array}{l}-1.024^{\mathrm{c}} \\
(4.390)\end{array}$ \\
\hline$D_{4}(\Delta C)$ & $\begin{array}{l}-0.080 \\
(0.269)\end{array}$ & $\begin{array}{l}-0.012 \\
(0.041)\end{array}$ & $\Delta C$ & $\begin{array}{l}0.894^{\mathrm{c}} \\
(13.964) \\
\end{array}$ & $\begin{array}{r}0.071^{\mathrm{c}} \\
(12.716) \\
\end{array}$ \\
\hline$\Delta(X q) /\left(q_{i} q_{j}\right)$ & $\begin{array}{l}-0.029 \\
(0.064)\end{array}$ & $\begin{array}{l}-0.032 \\
(0.093)\end{array}$ & $\Delta(X q) /\left(q_{i} q_{j}\right)$ & $\begin{array}{l}-0.049 \\
(0.245)\end{array}$ & $\begin{array}{l}-0.078^{\mathrm{c}} \\
(5.348)\end{array}$ \\
\hline$m_{c}$ & $\begin{array}{l}0.216^{\mathrm{c}} \\
(4.343)\end{array}$ & $\begin{array}{l}0.139^{\mathrm{c}} \\
(3.450)\end{array}$ & $m_{c}$ & $\begin{array}{l}0.016 \\
(0.644)\end{array}$ & $\begin{array}{l}-0.002 \\
(1.086)\end{array}$ \\
\hline $\begin{array}{l}\text { Category } \\
\text { Dummy } \\
\text { Variables }\end{array}$ & 1 Sig. & $\begin{array}{l}\text { None } \\
\text { Sig. }\end{array}$ & $\begin{array}{l}\text { Category } \\
\text { Dummy } \\
\text { Variables }\end{array}$ & $\begin{array}{l}\text { None } \\
\text { Sig. }\end{array}$ & 1 Sig. \\
\hline Intercept & $\begin{array}{l}-1.679 \\
(3.119)\end{array}$ & $\begin{array}{l}-1.033 \\
(2.209)\end{array}$ & Intercept & $\begin{array}{l}-0.056 \\
(0.260)\end{array}$ & $\begin{array}{l}0.025 \\
(1.065)\end{array}$ \\
\hline $\begin{array}{l}\text { Log } \\
\text { Likelihood }\end{array}$ & -233.821 & -243.213 & S.E.E. & 1.436 & 0.141 \\
\hline McFadden $\mathrm{R}^{2}$ & 0.055 & 0.030 & $\mathrm{R}^{2}$ (adj.) & 0.326 & 0.433 \\
\hline $\begin{array}{l}\text { Percent } \\
\text { Correctly } \\
\text { Classified }\end{array}$ & 62.84 & 58.47 & & n.a. & n.a. \\
\hline
\end{tabular}

${ }^{1}$ Robust standard errors computed using quasi-maximum likelihood methods.

${ }^{2}$ White heteroskedasticity-consistent standard errors and covariances. 
Table 5.3

SUMMARY OF HYPOTHESES TESTING RESULTS

\begin{tabular}{|l|l|l|l|l|c|}
\multicolumn{4}{c}{} & \multicolumn{3}{c}{$\begin{array}{c}\text { Binomial } \\
\text { Logit }\end{array}$} & \multicolumn{2}{c|}{\begin{tabular}{c} 
Generalized \\
\multicolumn{2}{c|}{ Least Sqrs. }
\end{tabular}} \\
\hline Hypothesis & Explanatory Variable & MCI & MNL & MCI & MNL \\
\hline H1: Neg. Cross Elas. & $B_{j} \times I_{i}$ & $\sqrt{ }$ & $\sqrt{ }$ & $\sqrt{ }$ & $\mathbf{x}$ \\
\hline H2: Neg. Cross Elas. & $C_{j}$ & $\sqrt{ }$ & $\sqrt{ }$ & $\mathbf{x}$ & $\mathbf{x x}$ \\
\hline H3: Neg. Cross Elas. & $E_{i i}^{*}$ & $\mathbf{x}$ & n.a. & $\sqrt{ }$ & n.a. \\
\hline
\end{tabular}

$\sqrt{ }=$ Confirming evidence: estimated coefficient for variable has hypothesized sign and is statistically significant, $\mathrm{p} \leq 0.05,1$ tail test.

$\mathbf{x}=$ Contradictory evidence: estimated coefficient has opposite sign from that hypothesized, but is not statistically significant, $\mathrm{p}>0.10$, two tail test.

$\mathbf{x x}=$ Contradictory evidence: estimated coefficient has opposite sign from that hypothesized and is statistically significant, $\mathrm{p} \leq 0.10$, two tail test.

n.a. $=$ Not applicable 


\section{REFERENCES}

Ainslie, Andrew and Peter E. Rossi (1998), "Similarities in Choice Behavior Across Product Categories,” Marketing Science, 17 (Spring), 91-106.

Allenby, Greg M. and Peter E. Rossi (1991a), "There Is No Aggregation Bias: Why Macro Logit Models Work," Journal of Business and Economic Statistics, 9 (January), 1-14.

(1991b), "Quality Perceptions and Asymmetric Switching Between Brands," Marketing Science, 10 (Summer), 185-204.

Bell, David E., Ralph L, Keeney, and John D, C, Little (1975), "A Market Share Theorem," Journal of Marketing Research, 12 (May), 136-141.

Bell, David R., Jeongwen Chiang, and V. Padmanabhan (1999), “The Decomposition of Promotional Response,” Marketing Science, 18 (Fall), 504-526.

Berndt, Ernst R. and Alvin J. Silk (1993), “Consistency Requirements and the Specification of Asymmetric Attraction Models of Aggregate Market Share,” Working Paper 93-013, Harvard Business School, April.

Ben-Akiva, Moshe and Steven R. Lerman (1985), Discrete Choice Analysis: Theory and Application to Travel Demand. Cambridge, MA: MIT Press.

Besanko, David, Sachin Gupta and Dipak Jain (1998), “Logit Demand Estimation Under Competititive Pricing Behavior: An Equilibrium Framework” Management Science, Vol 44, No. 11 Part 1 of 2 (November), 1533-1547.

Bijmolt, Tammo H. O. and Harald J. Van Heerde (2001), "Meta-Analysis in Marketing When Studies Contain Multiple Measurements,” Marketing Letter, 12 (May), 157-169.

, and Rik G.M. Peeters (2005), "New

Empirical Generalizations on the Determinants of Price Elasticity,” Journal of Marketing Research, 42 (May), 141-156.

Blattberg, Robert C. and Kenneth J. Wisniewski (1989), "Price-Induced Patterns of Competition," Marketing Science, 8 (Fall), 291-309.

Bucklin, Randolph E., Gary J. Russell and V. Srinivasan (1998), “A Relationship Between Market Share Elasticities and Brand Switching Probabilities,” Journal of Marketing Research, 35 (February), 99-113.

Chintagunta, Pradeep K., Dipak C. Jain and Naufel J. Vilcassim (1991) "Investigating Heterogeneity in Brand Preferences in Logit Models for Panel Data," Journal of Marketing Research, 28 (November), 417-428.

(2001) "Research Note: Endogeneity and Heterogeneity in a Probit Demand Model: Estimation Using Aggregate Data,” Marketing Science, Vol 20(4), Fall, 442-456.

Christen, Markus, Sachin Gupta, John C. Porter, Richard Staelin, and Dick R. Wittink (1997), "Using Market-Level Data to Understand Promotion Effects in a Nonlinear Model,” Journal of Marketing Research, 34 (August), 322-34.

Cooper, Lee G, and Masao Nakanishi (1988), Market Share Analysis. Boston: Kluwer. 
(1993), "Market Share Models," in J. Eliasberg and G.L. Lilien, eds., Handbook of Operations Research and Management Science: Marketing, Vol. 5, Chapt. 6. New York: North-Holland, 259-314.

Deaton, Angus and John Muellbauer (1980), Economics and Consumer Behavior, New York: Cambridge University Press.

Diewert, W. Erwin (1974), "Applications of Duality Theory," in Michael D, Intriligator and David A, Kendrick, eds., Frontiers of Quantitative Economics, Amsterdam: NorthHolland Publishing Company, Vol., II, 106-171.

(1977), "Generalized Slutsky Conditions for Aggregate Consumer Demand Functions," Journal of Economic Theory, 15 (August), 353-362.

(1980), "Symmetry Conditions for Market Demand Functions," Review of Economic Studies, 47 (April), 595-601.

Fok, Dennis, Hans Frances, and Richard Paap (2002), "Econometric Analysis of the Market Share Attraction Model,” in P. H. Frances and A. L. Montgomery, eds., Econometric Models in Marketing. New York: JAI/Elsevier, 223-256.

Goldstein, Harvey and Jon Rasbash (1992), "Efficient Computational Procedures for the Estimation of Parameters in Multilevel Models Based on Iterative Generalized Least Squares," Computational Statistics \& Data Analysis, 13 (January), 63-71.

Gupta, Sunil (1988), "Impact of Sales Promotions On When, What, and How Much To Buy,” Journal of Marketing Research, 25 (November), 342-355.

Gupta, Sachin, Pradeep Chintagunta, Anil Kaul, and Dick R. Winnick (1996), "Do Household Scanner Data Provide Representative Inferences from Brand Choices: A Comparison with Store Data,” Journal of Marketing Research, 33 (November), 383-398.

Hausman Jerry, Gregory Leonard, and J. Douglas. Zona (1994), "Competitive Analysis with Differentiated Products", Annales D'Economie et de Statistique, 34, (April-June), 315337.

Hanssens, Dominique M., Leonard J. Parsons and Randall L. Schultz (2001), Market Response Models, $2^{\text {nd }}$ ed. Boston: Kluwer.

Hoch, Stephen J., Byung-Do Kim, Alan L. Montgomery, and Peter E. Rossi (1996), "Determinants of Store-Level Price Elasticity," Journal of Marketing Research, 32 (February), 17-29.

Houston, Franklin S., Vinay Kanetkar, Craig Stacey and Doyle L. Weiss (1991), "Market Share Models with Logical and Economic Consistency," unpublished paper presented at the Scanner Conference, University of California at Los Angeles, January. , and Doyle L. Weiss (1991), "Simplified Estimation Procedures for MCI and MNL Models: A Comment," unpublished paper.

Kadiyali, Vrinda, K. Sudhir, and Vithala R. Roa (2001), "Structural Analysis of Competitive Behavior: New Empirical Industrial Organization Methods in Marketing,” International Journal of Research in Marketing, 18, 161-186. 
Little, John D.C. (1998), "Integrated Measures of Sales, Merchandising, and Distribution,” International Journal of Research in Marketing, 15, (December), 473-485.

Kamakura, Wagner A. and Gary J. Russell (1989) “A Probabilistic Choice Model for Market Segmentation and Elasticity Structure,” Journal of Marketing Research, 16 (November), 379-390.

McGuire, Timothy W. and Doyle L. Weiss (1976), "Logically Consistent Market Share Models II," Journal of Marketing Research, 13 (August), 296-302.

and Franklin S, Houston (1977), "Consistent Multiplicative Market Share Models," in Barnett A, Greenwood and Danny N, Bellinger, eds., Contemporary Marketing Thought, 1977 Educators' Proceedings, Series No, 41, Chicago: American Marketing Association, 129-34.

Montgomery, Alan L. (1997), "Creating Micro-Marketing Pricing Strategies Using Supermarket Scanning Data,” Marketing Science, 16, No. 4, 315-337.

and Peter E. Rossi (1999), "Estimating Price Elasticities with Theory-Based Priors,” Journal of Marketing Research, 36 (November), 413-423.

(2002), "Reflecting Uncertainty About Economic Theory When Estimating Consumer Demand,” in P. H. Frances and A. L. Montgomery, eds., Econometric Models in Marketing. New York: JAI/Elsevier, 257-294.

Naert, Philippe A. and Alain Bultez (1973), "Logically Consistent Market Share Models," Journal of Marketing Research, 10 (August), 334-340.

Nevo, Aviv (2001) "Measuring Market Power in the Ready-to-Eat Cereal Industry," Econometrica, 69 (2) 307-342.

Nijs, Vincent R., Marnik G. Dekimpe, Jan-Benedict E.M. Steenkamp, and Dominique M. Hanssens (2001), “The Category-Demand Effects of Price Promotions,” Marketing Science, 20 (Winter), 1-22.

Sethuraman, Raj, V. Srinivasan, and Doyle Kim (1999), “Asymmetric and Neighborhood Cross-Price Effects: Some Empirical Generalizations,” Marketing Science, 18 (Winter), 2341.

Sonnenschein, Hugo (1973), "Do Walras' Identity and Continuity Characterize the Class of Community Excess Demand Functions?" Journal of Economic Theory, 6, 345-54.

Van Heerde, Harald J., Sachin Gupta and Dick R. Wittink (2003), "Is 75\% of the Sales Promotion Bump Due to Brand Switching? No, only 33\% Is,” Journal of Marketing Research, 40 (November), 481-491.

Weverbergh, Marcel, Phillppe Naert and Alain Bultez (1981), "Logically Consistent Market Share Models Revisited," Revue Belge de Statistique d'Informatique et de Recherche Operationelle, 21, (March), 3-37. 


\section{APPENDIX A: Derivation of the Slutsky Equation in Share Elasticity Form}

Following Deaton and Muellbauer (1980, p. 45), we may write the well-known Slutsky equation from consumer demand theory (in the notation used throughout this paper) for any $i$ and $j$ :

$$
\frac{\partial g_{i}}{\partial X_{j}}=\frac{\partial h_{i}}{\partial X_{j}}-q_{j} \frac{\partial q_{i}}{\partial X_{m+1}}
$$

where

$$
\begin{aligned}
& q_{i}=g_{i}\left(X_{m+1}, \mathbf{X}\right) \equiv h_{i}(u, \mathbf{X}) \\
& u=\Psi\left(X_{m+1}, \mathbf{X}\right)
\end{aligned}
$$

and

$$
\begin{aligned}
X_{j} & =\text { unit price of good } j \\
\mathbf{X} & =\text { vector of prices for choices } \mathrm{j}=1, \ldots \mathrm{m} \\
q_{j} & =\text { quantity demanded of good } j \\
X_{m+1} & =\text { consumer's total budget or expenditures }=\sum_{\mathrm{v}=1}^{\mathrm{m}} \mathrm{X}_{\mathrm{j}} \mathrm{q}_{\mathrm{v}} \\
u & =\text { utility } \\
g_{i}() & =\text { Marshallian (uncompensated) demand function } \\
h_{i}() & =\text { Hicksian compensated demand function } \\
\Psi() & =\text { indirect utility function }
\end{aligned}
$$

Given that the Slutsky equation (A.1) relates to quantities demanded but the present interest is in market shares, we need to move from a quantity elasticity to a quantity share elasticity, where "share" refers to good $i$ 's share of total demand, i.e., where

$$
s_{i}=\frac{q_{i}}{\sum_{v=1}^{m} q_{v}}, \quad \forall i=1, \ldots, m
$$

And, by (A.2) we can use $q_{i}$ as the Hicksian demand $q_{i}=h_{i}(u, \mathbf{X})$. Note that:

$$
\frac{\partial \ln S_{i}}{\partial \ln X_{j}}=\frac{X_{j}}{s_{i}} \frac{\partial s_{i}}{\partial X_{j}}
$$

Substituting the Hicksian demand function into (A.3) and differentiating good $i$ 's share with respect to $j$ 's price, we obtain:

$$
\frac{\partial s_{i}}{\partial X_{j}}=\left\{\frac{\sum_{v=1}^{m} q_{v} \frac{\partial q_{i}}{\partial X_{j}}-q_{i} \frac{\partial \sum_{v=1}^{m} q_{v}}{\partial X_{j}}}{\left\{\sum_{v=1}^{m} q_{v}\right\}^{2}}\right\}
$$

Hence: 


$$
\begin{gathered}
\frac{\partial \ln S_{i}}{\partial \ln X_{j}}=\frac{X_{j}\left(\sum_{v=1}^{m} q_{v}\right)}{q_{i}}\left\{\frac{\sum_{v=1}^{m} q_{v} \frac{\partial q_{i}}{\partial X_{j}}-q_{i} \frac{\partial \sum_{v=1}^{m} q_{v}}{\partial X_{j}}}{\left\{\sum_{v=1}^{m} q_{v}\right\}^{2}}\right\} \\
=\frac{\partial \ln q_{i}}{\partial \ln X_{j}}-\frac{\partial \ln \left(\sum_{v=1}^{m} q_{v}\right)}{\partial \ln X_{j}}
\end{gathered}
$$

The second term in the brackets on the right hand side of (A.6) is the elasticity of total demand with respect to the price of good $j$. Further, it is readily shown that the first term in the brackets on the right hand side of this equation (A.6) is the familiar Slutsky equation written in elasticity form, i.e.:

$$
\frac{\partial \ln q_{i}}{\partial \ln X_{j}}=\left(\frac{\partial \ln q_{i}}{\partial \ln X_{j}}\right)_{\mathrm{u}=\text { constant }}-\left(B_{j} \frac{\partial \ln q_{i}}{\partial \ln X_{m+1}}\right)_{\text {Price }=\text { constant }}
$$

where $B_{j}$ is the budget share of the $j$ th good,

$$
B_{j}=\frac{X_{j} q_{j}}{\sum_{v=1}^{m} X_{j} q_{v}}
$$

Substituting (A.7) into (A.6) yields:

$$
\frac{\partial \ln S_{i}}{\partial \ln X_{j}}=\left(\frac{\partial \ln q_{i}}{\partial \ln X_{j}}\right)_{\mathrm{u}=\text { constant }}-\left(B_{j} \frac{\partial \ln q_{i}}{\partial \ln X_{m+1}}\right)_{\text {Price=constant }}-\frac{\partial \ln \left(\sum_{v=1}^{m} q_{v}\right)}{\partial \ln X_{j}}
$$

Note that in general, whenever the conventional price elasticity in (A.6) is asymmetric, so too is the share elasticity in (A.8). But in addition, the share elasticity (A.8) will be asymmetric if the elasticity of total quantity with respect to price differs considerably between goods $i$ and $j$. 


\section{Appendix B: Ancillary Summary Statistics}

Table B4.4
SUMMARY STATISTICS FOR ESTIMATES OF
INCOME AND CATEGORY DEMAND ELASTIC
\begin{tabular}{|l|l|c|}
\hline $\mathrm{n}=127$ brands $)$ \\
\hline & $\begin{array}{c}\text { Income } \\
\text { Elasticity }\end{array}$ & $\begin{array}{c}\text { Category Demand } \\
\text { Elasticity }\end{array}$ \\
\hline Mean & 0.671 & -0.349 \\
\hline Median & 0.737 & -0.225 \\
\hline Max & 1.337 & 0.240 \\
\hline Min & 0.052 & -1.841 \\
\hline Std Deviation & 0.346 & 0.434 \\
\hline
\end{tabular}

Table B5.1A1

SUMMARY STATISTICS FOR VARIABLES IN MODELS USED TO TEST H1-H3 ( $\mathrm{n}=732$ Cross Elasticity Estimates)

\begin{tabular}{|l|r|c|r|c|r|r|c|c|r|r|r|r|}
\hline & $\begin{array}{c}\mathrm{E}_{\mathrm{ij}} \\
\mathrm{MCI}\end{array}$ & $\begin{array}{c}\mathrm{D}\left(\mathrm{E}_{\mathrm{ij}}<0\right) \\
\mathrm{MCI}\end{array}$ & $\begin{array}{c}\mathrm{E}_{\mathrm{ij}} \\
\mathrm{MNL}\end{array}$ & $\begin{array}{c}\mathrm{D}\left(\mathrm{E}_{\mathrm{ij}}<0\right) \\
\mathrm{MNL}\end{array}$ & $\begin{array}{c}\mathrm{E}^{*} \\
\mathrm{MCI}\end{array}$ & $\begin{array}{c}\mathrm{E}^{*} \\
\mathrm{MNL}\end{array}$ & $\mathrm{B}_{\mathrm{j}}$ & $\mathrm{I}_{\mathrm{i}}$ & $\mathrm{B}_{\mathrm{j}} \mathrm{I}_{\mathrm{i}}$ & $\mathrm{C}_{\mathrm{j}}$ & $X_{i} / q_{j}$ & $\mathrm{~m}$ \\
\hline Mean & 0.521 & 0.302 & 0.062 & 0.311 & -1.046 & -0.455 & 0.139 & 0.493 & 0.078 & -0.382 & 0.271 & 8.623 \\
\hline Median & 0.427 & 0.000 & 0.009 & 0.000 & -0.960 & -0.356 & 0.094 & 0.398 & 0.039 & -0.191 & 0.125 & 9.000 \\
\hline Max & 6.635 & 1.000 & 0.711 & 1.000 & 0.778 & 0.070 & 0.782 & 1.337 & 0.726 & 0.437 & 3.715 & 12.000 \\
\hline Min & -7.107 & 0.000 & -0.325 & 0.000 & -3.232 & -2.124 & 0.023 & 0.086 & -0.018 & -4.346 & 0.001 & 2.000 \\
\hline Std. Dev. & 0.459 & 0.459 & 0.135 & 0.463 & 0.636 & 0.463 & 0.131 & 0.343 & 0.103 & 0.632 & 0.430 & 2.872 \\
\hline $\begin{array}{l}\text { Coef. of } \\
\text { Var. }\end{array}$ & 2.400 & 1.520 & 2.177 & 1.489 & 0.608 & 1.018 & 0.942 & 0.696 & 1.321 & 1.655 & 1.587 & 0.333 \\
\hline
\end{tabular}


Table B5.1A2

ZERO-ORDER CORRELATIONS AMONG VARIABLES IN MODELS USED TO TEST H1-H3

( $\mathrm{N}=732$ Cross Elasticity Estimates)

\begin{tabular}{|c|c|c|c|c|c|c|c|c|c|c|c|}
\hline & $\begin{array}{l}E_{i j} \\
M C I\end{array}$ & $\begin{array}{c}D\left(E_{i j}<0\right) \\
M C I\end{array}$ & $\begin{array}{c}E_{i j} \\
M N L \\
\end{array}$ & $\begin{array}{c}D\left(E_{i j}<0\right) \\
M N L\end{array}$ & $B_{j}$ & $I_{i}$ & $B_{j} I_{i}$ & $C_{j}$ & $\begin{array}{c}E_{i i}^{*} \\
(M C I / M N L)\end{array}$ & $X_{i} / q_{j}$ & $m$ \\
\hline & & & & & & & & & & & \\
\hline$B_{j}$ & 0.463 & -0.286 & 0.607 & -0.407 & ----- & & & & & & \\
\hline$I_{i}$ & 0.082 & -0.116 & 0.064 & -0.288 & -0.203 & ----- & & & & & \\
\hline$B_{j} I_{i}$ & 0.325 & -0.218 & 0.443 & -0.118 & 0.826 & 0.587 & ------ & & & & \\
\hline$C_{j}$ & 0.026 & 0.075 & 0.094 & 0.085 & 0.096 & -0.447 & -0.052 & ----- & & & \\
\hline $\begin{array}{l}E_{i i}^{*} \\
(M C I / M N L)\end{array}$ & $\begin{array}{l}-0.051 \\
----\end{array}$ & $\begin{array}{l}0.037 \\
----\end{array}$ & $\begin{array}{l}----- \\
0.005\end{array}$ & $\begin{array}{l}----- \\
0.045\end{array}$ & $\begin{array}{l}0.038 \\
0.043\end{array}$ & $\begin{array}{l}-0.022 \\
-0.456\end{array}$ & $\begin{array}{r}0.010 \\
-0.142\end{array}$ & $\begin{array}{r}-0.199 \\
0.318\end{array}$ & ------ & & \\
\hline$X_{i} / q_{j}$ & 0.108 & -0.013 & 0.019 & -0.001 & 0.298 & -0.073 & 0.167 & 0.097 & $\begin{array}{l}0.217 \\
0.300\end{array}$ & ----- & \\
\hline$m$ & -0.172 & 0.155 & -0.202 & 0.131 & -0.538 & -0.541 & -0.690 & -0.074 & $\begin{array}{l}0.018 \\
0.057\end{array}$ & -0.212 & -- \\
\hline
\end{tabular}

Table B5.2A1

SUMMARY STATISTICS FOR VARIABLES IN MODELS USED TO ANALYZE SIGNASYMMETRIES IN MCI CROSS ELASTICITIES

( $\mathrm{n}=366$ Pairs of MCI Cross Elasticity Estimates)

Binomial Logit Model

\begin{tabular}{|c|c|c|c|c|c|c|c|c|c|c|c|c|}
\hline & $\begin{array}{l}D \\
(S S)\end{array}$ & $\begin{array}{c}D_{1} \\
(\Delta B)\end{array}$ & $\begin{array}{c}D_{2} \\
(\Delta I)\end{array}$ & $\begin{array}{c}D_{3} \\
(\Delta B I)\end{array}$ & $\begin{array}{c}D_{4} \\
(\Delta C)\end{array}$ & $\Delta E$ & $\Delta B$ & $\Delta I$ & $\triangle B I$ & $\Delta C$ & $\Delta X q / q_{i} q_{j}$ & $m$ \\
\hline Mean & 0.407 & 0.544 & 0.464 & 0.467 & 0.481 & -0.040 & 0.010 & -0.064 & -0.006 & -0.157 & -0.040 & 8.622 \\
\hline Media & 0.000 & 1.000 & 0.000 & 0.000 & 0.000 & 0.051 & 0.011 & -0.031 & -0.001 & -0.034 & -0.003 & 8.000 \\
\hline Max & 1.000 & 1.000 & 1.000 & 1.000 & 1.000 & 6.545 & 0.688 & 1.132 & 0.371 & 4.176 & 2.859 & 12.000 \\
\hline Min & 0.000 & 0.000 & 0.000 & 0.000 & 0.000 & -7.194 & -0.451 & -1.191 & -0.410 & -4.319 & -1.868 & 2.000 \\
\hline Std. Dev. & 0.492 & 0.499 & 0.499 & 0.500 & 0.497 & 1.749 & 0.169 & 0.412 & 0.078 & 0.862 & 0.397 & 2.874 \\
\hline $\begin{array}{l}\text { Coef. of } \\
\text { Variation }\end{array}$ & 1.209 & 0.917 & 1.075 & 1.071 & 1.122 & 43.725 & 16.900 & 6.438 & 13.000 & 5.490 & 9.925 & 0.333 \\
\hline
\end{tabular}


Table B5.2A2

ZERO ORDER CORRELATIONS AMONG VARIABLES IN BINOMIAL LOGIT MODEL USED TO ANALYZE SIGN-ASYMMETRIES IN MCI CROSS ELASTICITIES $(\mathrm{n}=366$ Pairs of MCI Cross Elasticity Estimates)

\begin{tabular}{|l|c|c|c|c|c|c|c|}
\hline & $D(S S)$ & $D_{1}(\Delta B)$ & $D_{2}(\Delta I)$ & $D_{3}(\Delta B I)$ & $D_{4}(\Delta C)$ & $\Delta X q / q_{i} q_{j}$ & $m$ \\
\hline$D(S S)$ & 1.000 & & & & & & \\
\hline$D_{1}(\Delta B)$ & -0.022 & 1.000 & & & & & \\
\hline$D_{2}(\Delta I)$ & -0.058 & -0.621 & 1.000 & & & & \\
\hline$D_{3}(\Delta B I$ & -0.007 & 0.264 & 0.116 & 1.000 & & & \\
\hline$D_{4}(\Delta C)$ & -0.011 & -0.641 & 0.438 & -0.305 & 1.000 & & \\
\hline$\Delta X q / q_{i} q_{j}$ & -0.043 & -0.489 & 0.442 & -0.225 & 0.438 & 1.000 & \\
\hline$m$ & 0.214 & 0.157 & -0.074 & -0.005 & -0.123 & -0.172 & 1.000 \\
\hline
\end{tabular}

Table 5.2A3

ZERO ORDER CORRELATIONS AMONG VARIABLES IN REGRESSION MODEL USED TO ANALYZE SIGN-ASYMMETRIES IN MCI CROSS ELASTICITIES ( $\mathrm{n}=366$ Pairs of MCI Cross Elasticity Estimates)

\begin{tabular}{|l|l|r|r|r|r|l|l|}
\hline & \multicolumn{1}{|l}{$\Delta \mathrm{E}$} & \multicolumn{1}{c|}{$\Delta \mathrm{B}$} & \multicolumn{1}{c|}{$\Delta \mathrm{I}$} & $\Delta \mathrm{BI}$ & $\Delta \mathrm{C}$ & $\Delta X q / q_{i} q_{j}$ & $m$ \\
\hline$\Delta E$ & 1.000 & & & & & & \\
\hline$\Delta B$ & -0.483 & 1.000 & & & & & \\
\hline$\Delta I$ & 0.403 & -0.743 & 1.000 & & & & \\
\hline$\Delta B I$ & -0.285 & 0.706 & -0.133 & 1.000 & & & \\
\hline$\Delta C$ & 0.567 & -0.665 & 0.656 & -0.282 & 1.000 & & \\
\hline$\Delta X q / q_{i} q_{j}$ & 0.305 & -0.649 & 0.550 & -0.362 & 0.483 & 1.000 & \\
\hline$m$ & -0.013 & 0.096 & -0.147 & 0.102 & -0.088 & -0.172 & 1.000 \\
\hline
\end{tabular}


Table B5.2B1

SUMMARY STATISTICS FOR VARIABLES IN REGRESSION MODEL USED TO ANALYZE SIGN-ASYMMETRIES IN MNL CROSS ELASTICITIES

$$
\text { ( } \mathrm{n} \text { = } 366 \text { Pairs of MNL Cross Elasticity Estimates) }
$$

Binomial Logit Model Variables

\begin{tabular}{|c|c|c|c|c|c|c|c|c|c|c|c|c|}
\hline & $\begin{array}{l}D^{\prime} \\
(\Delta E)\end{array}$ & $\begin{array}{c}D_{1} \\
(\Delta B)\end{array}$ & $\begin{array}{l}D_{2} \\
(\Delta I)\end{array}$ & $\begin{array}{c}D_{3} \\
(\Delta B I)\end{array}$ & $\begin{array}{c}D_{4} \\
(\Delta C)\end{array}$ & $\Delta E$ & $\Delta B$ & $\Delta I$ & $\triangle B I$ & $\Delta C$ & $\Delta X q / q_{i} q_{j}$ & $m$ \\
\hline Mean & 0.437 & 0.544 & 0.464 & 0.467 & 0.443 & 0.003 & 0.010 & -0.064 & -0.006 & -0.157 & -0.040 & 8.623 \\
\hline Median & 0.000 & 1.000 & 0.000 & 0.000 & 0.000 & -0.000 & 0.011 & -0.031 & -0.001 & -0.034 & -0.003 & 9.000 \\
\hline Max & 1.000 & 1.000 & 1.000 & 1.000 & 1.000 & 0.721 & 0.688 & 1.132 & 0.371 & 4.176 & 2.859 & 12.000 \\
\hline Min & 0.000 & 0.000 & 0.000 & 0.000 & 0.000 & -0.616 & -0.451 & -1.191 & -0.410 & -4.319 & -1.868 & 2.000 \\
\hline Std. Dev. & 0.497 & 0.499 & 0.499 & 0.500 & 0.497 & 0.188 & 0.168 & 0.412 & 0.078 & 0.862 & 0.397 & 2.874 \\
\hline $\begin{array}{l}\text { Coef. of } \\
\text { Variation }\end{array}$ & 1.137 & 0.917 & 1.075 & 1.071 & 1.122 & 62.667 & 16.800 & 6.438 & 13.000 & 5.490 & 9.925 & 0.333 \\
\hline
\end{tabular}

Table B5.2B2

ZERO ORDER CORRELATIONS AMONG VARIABLES IN BINOMIAL LOGIT MODEL USED TO ANALYZE SIGN ASYMMETRIES IN MNL CROSS ELASTICITIES $(\mathrm{n}=366$ Pairs of MNL Cross Elasticity Estimates)

\begin{tabular}{|l|c|c|c|c|c|c|c|}
\hline & $D^{\prime}(\Delta E)$ & $D_{l}(\Delta B)$ & $D_{2}(\Delta I)$ & $D_{3}(\Delta B I)$ & $D_{4}(\Delta C)$ & $\Delta X q / q_{i} q_{j}$ & $m$ \\
\hline$D^{\prime}(\Delta E)$ & 1.000 & & & & & & \\
\hline$D_{l}(\Delta B)$ & -0.011 & 1.000 & & & & & \\
\hline$D_{2}(\Delta I)$ & -0.048 & -0.621 & 1.000 & & & & \\
\hline$D_{3}(\Delta B I)$ & -0.008 & 0.264 & 0.116 & 1.000 & & & \\
\hline$D_{4}(\Delta C)$ & -0.009 & -0.641 & 0.438 & -0.305 & 1.000 & & \\
\hline$\Delta X q / q_{i} q_{j}$ & 0.035 & -0.489 & 0.442 & -0.225 & 0.438 & 1.000 & \\
\hline$m$ & 0.179 & 0.157 & -0.074 & 0.005 & -0.123 & -0.172 & 1.000 \\
\hline
\end{tabular}


Table B5.2B3

ZERO ORDER CORRELATIONS AMONG VARIABLES IN REGRESSION MODEL USED TO ANALYZE SIGN-ASYMMETRIES MNL CROSS ELASTICITIES ( $\mathrm{n}=366$ Pairs of MNL Cross Elasticity Estimates)

\begin{tabular}{|l|r|r|r|r|r|r|c|}
\hline & \multicolumn{1}{|c|}{$\Delta E$} & \multicolumn{1}{c|}{$\Delta B$} & \multicolumn{1}{c|}{$\Delta I$} & \multicolumn{1}{c|}{$\Delta B I$} & \multicolumn{1}{c|}{$\Delta C$} & $\Delta X q / q_{i} q_{i}$ & $m$ \\
\hline$\Delta E$ & 1.000 & & & & & & \\
\hline$\Delta B$ & -0.663 & 1.000 & & & & & \\
\hline$\Delta I$ & 0.487 & -0.743 & 1.000 & & & & \\
\hline$\Delta B I$ & -0.452 & 0.706 & -0.133 & 1.000 & & & \\
\hline$\Delta C$ & 0.616 & -0.665 & 0.656 & -0.282 & 1.000 & & \\
\hline$\Delta X q / q_{i} q_{j}$ & 0.315 & -0.649 & 0.550 & -0.361 & 0.483 & 1.000 & \\
\hline$m$ & -0.012 & 0.096 & -0.147 & 0.102 & -0.088 & -0.172 & 1.000 \\
\hline
\end{tabular}

